\title{
Humean Scepticism as an Alternative in the Traditional Moral Realism and Moral Anti-Realism Debate
}

\author{
by \\ Courteney Crump
}

A thesis submitted to the Faculty of Graduate and Postdoctoral Affairs in partial fulfillment of the requirements for the degree of

Master of Arts

in

Philosophy

Carleton University

Ottawa, Ontario

(C) 2018, Courteney Crump 


\begin{abstract}
Traditionally, the realism and anti-realism debate within metaphysics has been restricted to a dichotomy between realism and anti-realism. This dichotomy trickles down to more specific areas within the debate. One of these areas effected by the traditional realism and anti-realism dichotomy is moral realism and moral anti-realism. This thesis focuses on moral realism and moral anti-realism, and shows that restricting the debate to only moral realism and moral anti-realism is a false dichotomy. It does this through providing an alternative option to the two traditionally given: Humean Scepticism. The goal of this thesis is to argue that Humean Scepticism is a viable third option in the moral realism and moral antirealism debate. This thesis demonstrates that scepticism should sometimes be taken seriously and acknowledged in some debates that it has traditionally been excluded from.
\end{abstract}




\section{Acknowledgements}

The years of my Master's degree have been a stressful rollercoaster full of highs and lows, and I would not be where I am, or who I am, today without the following people.

To start, I would like to thank my co-supervisors Dr. Gordon Davis and Dr. Melissa Frankel for the hours they put into helping me, and for such quick feedback turnaround times. I would also like to thank Dr. Annie Larivée for all her sage advice, and Dr. Christine Koggel for her clear feedback and guidance during the Research Seminar. This thesis also would not have been possible without the Department of Philosophy Administrator, Sandra Kirkpatrick, and the Department of Philosophy Graduate Administrator, Kristopher Waddell. I have said this many times, but I will say it again: Sandy and Kris are like the parents of the department, keeping us all organized.

Secondly, I would like to thank my cohort, and the Carleton University Department of Philosophy. The members of my cohort and I experienced a lot together, and they all gave constructive feedback during the Research Seminar and during discussions concerning our theses outside of class. More specifically, I need to thank Brandon Smith and Rebecca Robb for always being willing to lend an ear, and for helping to keep me grounded.

Thirdly, I would like to thank my parents, and friends outside of academia. My parents have supported me throughout my life, and continue to do so (no matter how long I stay in school). My friends outside of academia have reminded me that there is a life outside of academia, and that I need to enjoy it to live my life to the 
fullest. I would like to extend a special thank you to two of my best friends, Victoria Mabie and Roger Korth, for sticking with me through thick and thin. I know the stress of my Master's degree and my workload did not always make me the friend I should have been.

Last, but definitely not least, I would like to thank my dog, Charlie—even though he cannot read this or understand why I am thanking him. There is nothing quite like the unconditional love of a companion animal. He made me go outside and get fresh air when I was feeling overwhelmed and depressed, and I do not know what I would have done without him. 


\section{Table of Contents}

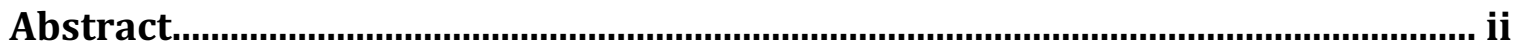

Acknowledgements.......................................................................................... iii

Table of Contents................................................................................................ v

1. Literature Review......................................................................................... 1

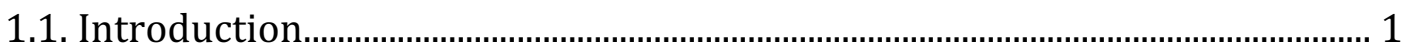

1.2. Realism vs. Anti-Realism.................................................................................... 5

1.3. Moral Realism vs. Moral Anti-Realism ............................................................ 13

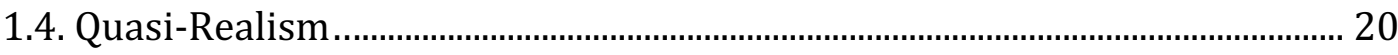

1.5. "Empiricism, Semantics, and Ontology" by Rudolf Carnap............................. 25

1.6. Pyrrhonian, Academic, or Methodological Scepticism?.................................... 27

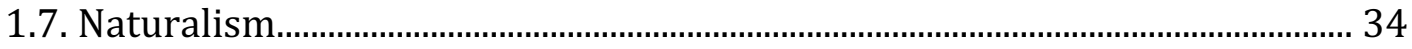

1.8. Hume: Realist, Anti-Realist, or Sceptic?............................................................ 41

1.9. An Interpretation of Hume's Philosophy........................................................... 44

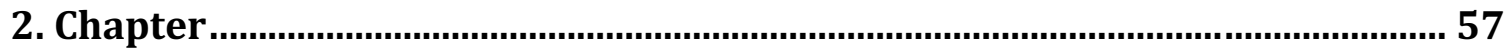

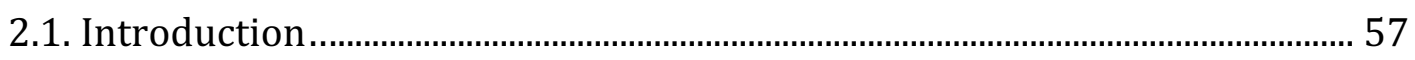

2.2. Humean Scepticism in A Treatise of Human Nature ....................................... 58

2.3. Humean Scepticism in An Enquiry concerning Human Understanding........ 72

2.4. Hume's Moral Philosophy.......................................................................................... 78

2.5. Hume's Method in An Enquiry concerning the Principles of Morals .............. 86

2.6. The Moral Realism and Moral Anti-Realism Debate: Humean Scepticism as

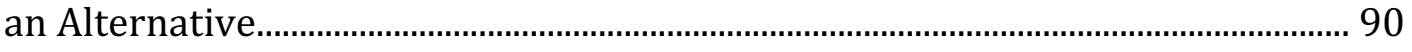

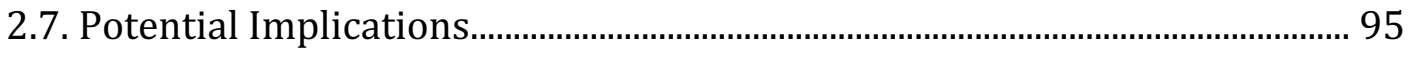

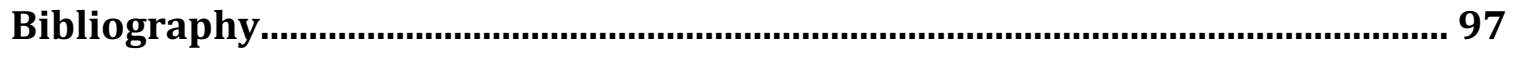




\section{Literature Review}

\subsection{Introduction}

While I am fascinated by metaethics, I have discovered that it is quite unpalatable for many people. So, when I decided to write my Master's thesis on metaethics, I struggled to think of a way to make my thesis interesting to a wider audience. I hope that I can make metaethics interesting and accessibleif only for the duration of my thesis. I am not sure why, but Ancient Greek philosophy is the first thing that jumped into my mind while I was considering how best to approach the topic of my thesis. Upon further reflection, it seemed to be organic to start with the beginning of the Western Philosophical Tradition, and then trace the conceptual framework to Hume and Early Modern philosophy.

To begin the metaethical journey of my thesis, I will give a quote from one of Plato's dialogues. My goal in this introduction is to start with a conception of knowledge, work my way towards metaphysics, and then finally get to metaethics. In the Theaetetus, Plato's Socrates says at 160e,

So we find the various theories have converged to the same thing: that of Homer and Heraclitus and all their tribe, that all things flow like streams; of Protagoras, wisest of men, that man is the measure of all things; and that of Theaetetus that, these things being so, knowledge proves to be perception. What about it, Theaetetus? Shall we say we have here your first-born child, the result of my midwifery? Or what would you say? ${ }^{1}$

To which, Theaetetus replies to Socrates in a positive manner: indeed this is his firstborn 'child'. Knowledge is perception, according to Theaetetus, and each person perceives things differently. This can be seen as a relativistic understanding of

1 Plato, Theaetetus, in Complete Works of Plato, ed. John M. Cooper, trans. M.J. Levett 
knowledge, and the dialogue goes on to try to show that it is a false understanding of knowledge.

What I find interesting is that knowledge of cold, on this understanding of knowledge, is based on the subjective perceiver feeling cold-same goes for heat, and multiple other physical sensations and objects. It could be said that our knowledge of physical sensations and objects is mind-dependent in the sense that our knowledge of these things is dependent on us perceiving them. Plato's Socrates goes on in the Theaetetus to argue for a different understanding of knowledge that is not mind-dependent. Socrates tries to lead us to a less relative understanding of knowledge that, it could be argued, is mind-independent-i.e. not dependent on a perceiver perceiving it. For example, the concepts of 'love' and 'beauty' can be thought of as abstract forms-unchanging and containing the perfection of those concepts.

For me, the contemplation of what knowledge is throughout the dialogue leads away from the dialogue just being about knowledge, and moves towards contemplations of what there is in the world (i.e. ontology). Contemplating perceptions such as seeing 'white snow' or 'a brown table' quickly develop into contemplating more abstract concepts such as 'love', and debating whether these abstract concepts can be perceived in the same way as the 'white snow' or 'a brown table'. Questions like, "Does this [insert abstract concept] exist in the world?" absolutely fascinate me. And, so the discussion is not just about knowledge, but is also about metaphysics—or, perhaps more accurately, what we can know about the nature of metaphysics. 
Moving into more contemporary metaphysical language, the discussion becomes centred on realism and anti-realism. Realism, loosely construed when contemplating abstract concepts, can be seen as stating that abstract concepts are mind-independent. Some realists go as far as Plato, and state that not only are these abstract concepts mind-independent, but that they also exist in the world-even if there was no person there to perceive them. Anti-realism, then, is the opposite of realism. It generally states that abstract concepts are mind-dependent, and potentially contingent on human beings.

My thesis is on this realism and anti-realism debate, or, I should say, what I see to be a false dilemma. My thesis looks at the realism and anti-realism dilemma from within a moral context, and so I am particularly interested in the status of moral facts (or claims, or propositions) and whether they are truth-apt (or not). Therefore, the topic of my thesis, most generally construed, is metaethics. More specifically, the topic of my thesis is dealing with the traditional moral realism and moral anti-realism debate in metaethics while denying that we must stay within this dichotomy to find answers to metaethical questions. The primary question I ask is this: are moral realism and moral anti-realism the only options open to us? My answer is no. I propose that scepticism, more specifically Humean Scepticism, is a third option available.

The reason why I call the traditional debate a false dilemma is because, even as far back as Plato, the sceptical position was not taken seriously, and, for at least 2500 years, the debate has been structured as solely a back and forth between realism and anti-realism. The big issue that I find startling is that, even though 
arguments have become more complicated and fine-tuned, realism and anti-realism have not really progressed over the past 2500 years of the dominant Western Philosophical Tradition. I think that this shows the dilemma to be getting us nowhere. So, I propose that taking a sceptical position concerning the ontological status of moral facts (or claims or propositions) might be an alternative to the traditional dichotomy, and could potentially help the debate along.

As I mentioned, I think that Humean Scepticism could be this sceptical alternative. I say 'Humean' rather than 'Hume's', because, as is the norm with Hume scholarship, no one agrees on any one interpretation and I have a particular way of reading Hume. My interpretation of Hume attributes to him a more ancient way of understanding his scepticism. The way I see Humean Scepticism is more in line with a particular Ancient Greek understanding of scepticism as epochē or agnostic (i.e. the suspension of judgement). This is in contrast to the more common understanding of scepticism as a methodological tool (for example, Descartes' use of scepticism in his Meditations on First Philosophy).

My thesis focuses on Hume, his scepticism, his naturalism as methodological, and a reading of Hume as a kind of consequentialist. I stress the importance of interpreting Hume's naturalism within the context of his scepticism in order to help keep his philosophy cohesive, and I think a similar approach can be taken when considering consequentialism in Hume's moral philosophy. The goal is to show that Humean Scepticism is a true third option in the moral realism and moral antirealism debate, and to give an account of a moral theory that may work well considering Hume's sceptical approach to metaphysics. I think that it is important to 
demonstrate that a normative ethical theory can function while maintaining an ontologically sceptical position, because it demonstrates that scepticism is something to take seriously and that it does belong in the moral realism and moral anti-realism debate.

In the words of someone I consider to be wise, obviously not me (and I dare say not Plato either),

[A]ll knowledge degenerates into probability; and this probability is greater or less, according to our experience of the veracity or deceitfulness of our understanding, and according to the simplicity or intricacy of the question. ${ }^{2}$

Knowledge "degenerates" into probability. Probability does not get you certainty. You cannot be certain of realism or anti-realism, so it would seem that you also cannot be certain of moral realism or moral anti-realism (since they just offer a more specific case of realism and anti-realism). Why not remain truly sceptical, and take an agnostic stance?

\subsection{Realism vs. Anti-Realism}

Stuart Brock and Edwin Mares begin the introduction of their book Realism and Anti-Realism with the following sentences,

Questions about the ultimate reality of things sometimes seem like silly questions to non-philosophers, but to philosophers they are questions of the utmost importance and deepest significance. It is not easy or straightforward to know when some contentious realm of entities is real, or to understand and appreciate what is at issue between those on each side of the dispute. ${ }^{3}$

2 David Hume, A Treatise of Human Nature, eds. David Fate Norton and Mary J. Norton (Oxford: Oxford University Press, 2009), 1.4.1.

${ }^{3}$ Stuart Brock and Edwin Mares, Realism and Anti-Realism, in Central Problems of Philosophy, ed. John Shand (Montreal and Kingston: McGill-Queen's University Press, 2007), 1. 
I will make a strong statement, and assume that the vast majority of people take for granted that the external world is Real ${ }^{4}$ and do not question particular aspects or domains in the, potentially, external world. Most people, or non-philosophers as Brock and Mares call them, take for granted that the chair over there Really exists. The applied physicist thinks that certain natural laws govern the external world, and are Real. The biologist believes that the cells they are studying are Real. The mathematician might think that natural numbers are Real. Questioning whether something Really exists in the world on the surface seems like something that does not need questioning—after all, sometimes we just need to live our lives (and that can be hard enough without questioning whether certain facts or entities Really do exist).

But, when we have a moment to reflect, and think about what we think is Real, questions do begin to arise. Perhaps questions about whether our perceptions are accurate accounts of the Real world. Can we trust that our eyesight is not deceiving us when we make everyday mistakes when judging how far an object is from us? How much of the Real world do we actually perceive? Now, consider numbers. Do numbers exist in the Real world? We can also consider whether moral facts exist in the Real world. Does the moral fact, 'It is wrong to kill,' exist in the Real world? Perhaps it is the philosopher's job to question such things in relation to metaphysics, more specifically ontology, but these abstract questions end up affecting belief and belief can affect the way we live our lives. Abstract metaphysical

\footnotetext{
${ }^{4}$ When I use the word Real with a capital "R", I mean mind-independently real in the ontological sense (i.e. that something exists in the external world, and is not constructed by mental states or is not mind-dependent).
} 
questions end up being of importance, and thousand plus year debates often stem from them.

While there are many different subsections of the debate concerning the Real world, the overarching dichotomy has historically been between realism and antirealism. Realists and anti-realists have debated each other since Hellenistic times in the Western Philosophical Tradition, and the debate is far from being resolved. The realists attack the anti-realists (and vice versa), and both the realists and antirealists debate definitions and intricacies within their own camps. Definitions and the fine-tuning of arguments are far from being settled for both realism and antireal-ism, but I think it is important to give a definition for both these terms in order to give context to the debate that I am trying to situate myself within.

I think that Brock and Mares' general definition of realism is a good place to start,

Realism about a particular domain is the conjunction of the following two theses: (i) there are facts or entities distinctive of that domain, and (ii) their existence and nature is in some important sense objective and mindindependent. Let us call the first thesis the "existence thesis" and the second thesis the "independence thesis". ${ }^{5}$

Brock and Mares admit that this definition is not without controversy, ${ }^{6}$ but it will work fine to give a general definition that allows understanding of what is meant when I use the word realism. ${ }^{7}$ In their definition, Brock and Mare distinguish between facts and entities when it comes to the "existence thesis". They do this to

${ }^{5}$ Brock and Mares, Realism and Anti-Realism, 2.

${ }^{6}$ Ibid, 3.

${ }^{7}$ I acknowledge that others may use different definitions-this is fine because the basic information that this definition gives us is present in many other definitions of realism. 
distinguish between those who might be realists about facts from those who might be realists about entities within a particular domain. One example that they use to show this is, "One might believe it is a fact that everything that goes up must come down without believing in gravitational fields [...]." ${ }^{\prime \prime}$ In this example, I could believe in a fact without asserting anything about the entities or properties of a domain. So, I can be a realist about facts, but not be a realist about an entity (or entities) of a domain (and vice versa).

The second thesis of their definition is the "independence thesis". This thesis states that the facts or entities from the first thesis are, in some way, objective and mind-independent. Objective, in this understanding, means universal (and not subjective), and mind-independent means that they exist in some way in a nonreliant relationship with a human mind (or minds). This second thesis can go as far as to assert that the fact(s) or entity/entities in a given domain can exist in the Real, external world, but it does not have to go this far. Some realists are content just to say that a fact or entity is objective and mind-independent without asserting anything about the status of said fact or entity in the Real world-as I said above, there is no consensus when it comes to defining realism.

Defining anti-realism is just as difficult as defining realism, because, again, there is no consensus. You could just say that anti-realism is the opposite of realism, but that is difficult to figure out given the lack of consensus when it comes to realism. The antithesis of the above definition of realism could look something like denying the existence thesis, denying the independence thesis, or denying both. An

\footnotetext{
8 Brock and Mares, Realism and Anti-Realism, 2.
} 
anti-realist can deny that there are "facts or entities distinctive of that [particular] domain," they can deny the thesis that these facts or entities of a particular domain are objective and mind-independent, or they can deny both these theses.

Simon Blackburn gives a more detailed definition of realism in the Oxford Dictionary of Philosophy, Third Edition (though, still along the lines of Brock and Mare's definition of realism),

A realist about a subject-matter $S$ may hold (i) that the kinds of things described by S exist; (ii) that their existence is independent of us, or not an artefact of our minds, or our language or conceptual scheme; (iii) that the statements we make in $\mathrm{S}$ are not *reducible to other kinds of statement, revealing them to be about some different subject-matter; (iv) that the statements we make in $S$ have *truth conditions, being straightforward descriptions of aspects of the world and made true or false by facts in the world; (v) that we are able to attain truths about $\mathrm{S}$, and that it is appropriate fully to believe things we claim in S. ${ }^{9}$

Blackburn then goes on to explain that there are "different oppositions" that can take issue with one (or more) of any of the above realist claims,

*Eliminativists think the $\mathrm{S}$ discourse should be rejected. Sceptics either deny (i) or deny our right to affirm it. *Idealists and *conceptualists deny (ii), *reductionists deny (iii), while *instrumentalists and *projectivists deny (iv). *Constructive empiricists deny (v). Other combinations are possible, and in many areas there is little consensus on the exact way a realist/anti-realist dispute should be constructed.10

Blackburn interestingly lumps anti-realism and scepticism together in his list of oppositions to the realist claims he mentions first, which is problematic. ${ }^{11}$ Though I

\footnotetext{
${ }^{9}$ Simon Blackburn, "realism/anti-realism," in the Oxford Dictionary of Philosophy, Third Edition (Oxford: Oxford University Press, 2016), 404.

10 Ibid.

11 This will become more clear in section 1.6. "Pyrrhonian, Academic, or Methodological Scepticism?" But, I will briefly address why grouping anti-realists and sceptics together is problematic here. Some forms of scepticism are used as a method or tool, and can be grouped with either realism or anti-realism. Other forms of scepticism remain agnostic, and cannot be grouped with either realism or antirealism.
} 
take issue with aspects of this more detailed definition, it gives further insight into the intricacies of the realism/anti-realism debate-and shows why it is difficult to give definitions of realism and its antithesis.

I would like to give an example to highlight a bit of the tension between the realists and the anti-realists when it comes to the ontological status of facts or entities within a particular domain. I will give an example concerning pure mathematics. James Nicholson defines pure mathematics in The Concise Oxford Dictionary of Mathematics (Fifth Edition) as follows,

The area of mathematics concerning the relationships between abstract systems and structures and the rules governing their behaviours, motivated by its intrinsic interest or elegance rather than its application to solving problems in the real world. Much modern applied mathematics is based on what was viewed as very esoteric pure mathematics when it was devised. For example, matrix algebra is now the cornerstone of video-game technologies, computeraided design, etc. ${ }^{12}$

Starting with this definition, I think two different, though traditional, ideas could emerge: one realist, the other anti-realist. There could be a mathematician who works on matrix algebra who is a realist about mathematics. Due to the practical application of matrix algebra, the mathematician could believe that matrix algebra exists in the Real world, mind-independently. There could also be a pure mathematician who strictly works in pure mathematics, and only works within the abstract realm of pure mathematics (and does not work on any practical application of pure mathematics). This mathematician could believe that numbers, say natural

12 James Nicholson, "pure mathematics," in The Concise Oxford Dictionary of Mathematics, Fifth Edition (Oxford: Oxford University Press, 2016), http://www.oxfordreference.com.proxy.library.carleton.ca/view/10.1093/acref/97 80199679591.001.0001/acref-9780199679591-e-2307. 
numbers, are constructed and mind-dependent, and therefore would be an antirealist about natural numbers. Both mathematicians work on pure mathematics, but hold different views about the ontological status of facts or entities within that domain.

Jesse M. Mulder in his paper "What Generates the Realism/Anti-Realism Dichotomy?", says that one way of expressing the disagreement between realists and anti-realists is

[that] realists urge that their theories describe the world as it mindindependently is, whereas anti-realists argue that the very categories employed in such purported descriptions are, after all, our own categories, and hence that the very idea of a mind-independent reality in the realist's sense is deeply mistaken. ${ }^{13}$

So, in the case of the two mathematicians, the realist mathematician who works on matrix algebra might think that their work on matrix algebra describes the world as it Really is, mind-independently; while the anti-realist mathematician might think that natural numbers, or even matrix algebra, are just mind-dependent descriptions based on "our own categories."

So far, the debate has been between realism and anti-realism, and a good question to ask is 'What causes, or forces, this dichotomy?' It does seem odd that realism and anti-realism have been the focused on options for thousands of years (within the Western philosophical canon). Mulder suggests that what causes this dichotomy has to do with "[...] finding skepticism unsatisfactory,"

[W] can either become realists but be at a loss as to how we can adjudicate between highly divergent realist metaphysical theories, or we can admit our alleged inability to discover the nature of the world as it is in itself and make do

${ }^{13}$ Jesse M. Mulder, "What Generates the Realism/Anti-Realism Dichotomy," Philosophica 84 (2012): 57. 
with the anti-realist restriction of our knowledge to the world as it is for uswhich in turn quickly leads to serious issues, such as a commitment to the idea of a reality-itself that is denied any content, that again motivates a return to realism. ${ }^{14}$

It is this view that scepticism is unsatisfactory that spurs the dichotomy between realism and anti-realism, according to Mulder. The scepticism has to do with, to use Mulder's language, "the world as it is in itself." The metaphysical sceptic thinks that we cannot know whether our perceptions of 'the world as it is in itself' (or Real, external world) are accurate representations or not, and so the sceptic suspends their judgement about 'the world as it is in itself.' Mulder thinks that scepticism is unsatisfactory for the realist and for the anti-realist in separate ways. The realist takes issue with the sceptic's claim that "we [cannot] justify knowledge of the worldin-itself," and the anti-realist takes issue with the sceptic's claim that "truth involve[s] correspondence with the world-in-itself."15

The sceptical metaphysical picture, according to Mulder, looks something like we cannot justify knowledge of the Real world and truth corresponds to the Real world, so therefore we cannot have truth. ${ }^{16}$ The realist's claim is that we can justify knowledge of the Real world (and have truth correspond to the Real world), and the anti-realists' claim is that truth corresponds with "the world as it is for us" (and so truth does not correspond to the Real world-but to our perceptions of the Real world). ${ }^{17}$ I do take issue with this understanding of scepticism (which will become more clear in sections 1.6, 2.2, and 2.3), but it does seem to be an accurate account of

\footnotetext{
${ }^{14}$ Ibid, 71-72.

15 Ibid, 71.

16 Ibid.

17 Ibid, 72.
} 
what has forced the traditional dichotomy between realism and anti-realism. The realist and the anti-realist both believe that, in some way, metaphysical scepticism (as described by Mulder) is problematic; they just disagree on how it is problematic.

\subsection{Moral Realism vs. Moral Anti-Realism}

One subsection, or domain, within the realism and anti-realism dichotomy is moral realism and moral anti-realism. Geoffrey Sayre-McCord says in the introduction to Essays on Moral Realism,

[...] the debate between realists and anti realists is deep and important. It affects our ontology, epistemology, and semantics. And in ethics, it makes a significant difference to our understanding of what (if anything) is valuable, to our account of moral disagreement, and to the importance we place on moral reflection. ${ }^{18}$

Given the importance Sayre-McCord places on the realism and anti-realism dichotomy, particularly in reference to ethics, it makes it exceptionally pertinent to clarify the dichotomy as it relates to moral realism and moral anti-realism.

Therefore, it is important to define what is meant by moral realism and moral antirealism, and give an example for each.

I will start by giving Sayre-McCord's definitions for realism and anti-realism, but—due to how broad they are-I will add more clarifying definitions. SayreMcCord defines realism as follows,

Wherever it is found, I'll argue, realism involves embracing just two theses: (1) the claims in question, when literally construed, are literally true or false (cognitivism), and (2) some are literally true. Nothing more. ${ }^{19}$

${ }^{18}$ Geoffrey Sayre-McCord, "Introduction: The Many Moral Realisms," in Essays on Moral Realism, ed. Geoffrey Sayre-McCord (Ithaca, NY: Cornell University Press, 1988), 2.

19 Ibid, 5. 
These theses pertain to truth-aptness, and what is meant is that a claim can be true or false in reference to what I have been calling the Real world (i.e. there is something in the external world that makes the claim true or false). He then defines anti-realism,

Correspondingly, there are two ways to be an anti-realist: embrace a noncognitivist analysis of the claims in question or hold that the claims of the disputed class, despite their being truth-valued, are none of them true (say, because they all share a false presupposition). ${ }^{20}$

Here, Sayre-McCord is mainly alluding to Emotivism (and related theories) and Error Theory. Emotivists are non-cognitivists while Error Theorists can be classified as cognitivists who believe in truth-aptness (but do not think that truth values, like true or false, correlate to the Real world-or that they always correlate to the Real world falsely). This is a narrow account of anti-realism, but does allude to the issues an anti-realist may take issue with (in this definition of realism). The non-cognitivist (i.e. Emotivist) would take issue with thesis (1), and the Error Theorist would take issue with thesis (2).

In his book Moral Realism: A Defence, Russ Shafer-Landau gives a more specific definition of moral realism as well as giving explicit definitions of cognitivism and non-cognitivism. Shafer-Landau initially says that "[realists] endorse the reality of a domain and do so in opposition to constructivists. Realism is sometimes contrasted with constructivism by invoking the claim that, for realists, morality is mind-independent." 2122 Though, he says that this is a lacking definition

\footnotetext{
20 Ibid.

${ }^{21}$ Russ Shafer-Landau, Moral Realism: A Defence (Oxford: Oxford University Press, 2009), 15.
} 
when it comes to moral realism. ${ }^{23}$ He subsequently goes on to give a more careful definition of moral realism,

The way I would prefer to characterize the realist position is by reference to its endorsement of the stance-independence of moral reality. Realists believe that there are moral truths that obtain independently of any perspective, in the sense that the moral standards that fix the moral facts are not made true by virtue of their ratification from within any given actual or hypothetical perspective. That a person takes a particular attitude toward a putative moral standard is not what makes the standard correct. ${ }^{24}$

"Stance-independence" is, for Shafer-Landau, a way of articulating that there is an aspect of "something's rightness or admirability [depending] crucially on an agent's attitudes," but "the dependence [...] is not a function of what anyone happens to think of it." 25 So, there is an aspect of mind-dependence (given morality being agentbased), but the truth of moral claims themselves is not dependent on any one particular agent (in this way, they are mind-independent).

This definition of moral realism highlights the cognitive aspect of it. And, on the cognitive theme-generally considered in line with realism (though some antirealists, like Error Theorists, are cognitivists)—-most simply put, cognitivism is the view that a fact (or claim or proposition), like a moral fact (or claim or proposition), can be true or false. ${ }^{26}$ Shafer-Landau says of cognitivism,

[A] view is cognitivist if it allows for a central class of judgements within a domain to count as beliefs, capable of being true or false in virtue of their more or less accurate representation of the facts within the domain. Moral realism

${ }^{22}$ By "constructivists" /"constructivism" here, Shafer-Landau means anti-realists/ anti-realism.

${ }^{23}$ Ibid.

24 Ibid.

25 Ibid.

${ }^{26}$ Or, 'truth-apt' - cognitivists think that claims, or facts, lean towards truth (or falsity), even if no claims, or facts, end up being ultimately true (or false). 
satisfies these conditions. Realists see moral judgements as beliefs, some of which are true, and true in virtue of correctly reporting moral facts. ${ }^{27}$

In other words, a more sophisticated rendition of my very simple definition of cognitivism. My point in quoting Shafer-Landau's definition of cognitivism is because it very explicitly biases cognitivism towards moral realism, and this is not something that is necessarily agreed upon within the metaethical literature on moral realism and moral anti-realism. ${ }^{28}$ Shafer-Landau's biased use of cognitivism in contrast to other held views on cognitivism reinforces that there is no agreed upon definition. This constant disagreement is a reoccurring theme throughout all domains of realism and anti-realism.

Getting back to definitions, Shafer-Landau defines moral anti-realism, or what he calls "constructivism", more generally as

[...] the idea that moral reality is constituted by the attitudes, actions, responses, or outlooks of persons, possibly under idealized conditions. In short, moral reality is constructed from states or activities (understood very broadly) undertaken from a preferred standpoint. 29

This is to mean that moral reality for the anti-realist is not stance-independent (i.e. a complicated way of saying that moral reality for the anti-realist is not objective). He associates the constructivist (anti-realist) view with non-cognitivism, and states that, according to non-cognitivism, "there are no moral facts or truths."30 So, Shafer-

27 Shafer-Landau, Moral Realism: A Defence, 17.

${ }^{28}$ This is controversial. As I have previously said, Error Theorists can claim to be cognitivists. But, also, views such as Simon Blackburn's quasi-realism might challenge the idea that only Error Theorist anti-realists can be cognitivists (therefore cognitivism should not be so strongly associated with realism).

${ }^{29}$ Shafer-Landau, Moral Realism: A Defence, 14.

${ }^{30}$ Ibid, 18. 
Landau claims that for the anti-realist there are no moral facts or truths (i.e. that moral claims for the anti-realist cannot be truth-apt). ${ }^{31}$

Now that I have given some possible understandings (i.e. definitions) of moral realism and moral anti-realism, I think it would help to not only clarify the views, but also the divide, by giving an example of a moral realist theory and an example of a moral anti-realist theory. I will start with an example of a moral antirealist theory before giving an example of a moral realist theory (the reason why I have chosen this order will become more apparent once I have articulated the theories).

The moral anti-realist theory I have chosen as an example is Gilbert Harman's theory that he articulates in his book The Nature of Morality: An Introduction to Ethics. Harman's main position is that ethics is relative (i.e. he supports moral relativity), and he is an anti-realist concerning ethics. To show this, he uses the difference in observation between physics and ethics. Harman says,

The observation of an event can provide observational evidence for or against a scientific theory in the sense that the truth of that observation can be relevant to a reasonable explanation of why that observation was made. A moral observation does not seem, in the same sense, to be observational evidence for or against any moral theory, since the truth or falsity of the moral observation seems to be completely irrelevant to any reasonable explanation of why that observation was made. ${ }^{32}$

One of the examples that he uses to show this difference in observation is the difference between a scientist observing a proton's vapour trail and you judging that children setting a cat on fire is wrong. In the case of the scientist, their observation

${ }^{31}$ Again, I recognize that this is controversial.

${ }^{32}$ Gilbert Harman, The Nature of Morality: An Introduction to Ethics (Oxford: Oxford University Press, 1977), 7. 
of the vapour trail seems to explain what they are observing. In the case of you judging that children setting a cat on fire is wrong, your judgment is based on belief that does not seem to directly, or indirectly, explain what you are observing. In the case of science, there seems to be direct observation of events (or the Real world) to justify a theory (or force the adaption of a theory). In the case of ethics, it seems completely based on belief, and not observation.

Harman goes so far as to say that ethics is not only not based on direct observation, but also not based on indirect observation. He does this towards the end of his introduction by introducing mathematics. ${ }^{33}$ He says that mathematics can indirectly support physics, and therefore observation, but ethics does not seem to even be able to do this.

In contrast to Harman, Nicholas L. Sturgeon articulates a moral realist view in his paper "Moral Explanations". ${ }^{34}$ Sturgeon's main project in this paper is to deny that Harman's theory leads to the kind of moral scepticism that Harman thinks it does (something more along the lines of moral anti-realism than moral scepticism). Sturgeon thinks that Harman's basic view actually leads to Sturgeon's own kind of moral realism. Sturgeon is an ethical naturalist (in his type of moral realism), but one that thinks that moral claims are not necessarily reducible to physical claims (since he thinks that we do not have language for all physical claims, moral claims could actually be describing physical things). And, even though moral claims are not necessarily reducible to physical claims, moral claims still factor into our

\footnotetext{
33 Ibid, 9-10.

${ }^{34}$ Nicholas L. Sturgeon, "Moral Explanations," in Essays on Moral Realism, ed. Geoffrey Sayre-McCord (Ithaca, NY: Cornell University Press, 1988), 229-255.
} 
explanation of the world. Sturgeon writes, “... I shall argue that moral facts do fit into our explanatory view of the world, and in particular into explanations of many moral observations and beliefs." 35

Sturgeon then goes on to say, "... it seems plausible to cite moral facts as part of an explanation of nonmoral facts, and in particular of people's forming the moral opinions they do."36 Sturgeon's emphasis is not on a 'perfect' moral theory that exists independently of us (as is the focus of some moral realists). Surgeon thinks,

[If] our moral theory were somehow hopelessly mistaken, but all the nonmoral facts remained exactly the same as they in fact are, then, since we do accept the moral theory, we would still draw exactly the moral conclusions we in fact do. [...] [W] should deny that it follows that moral facts play no role in explaining our moral judgments. ${ }^{37}$

For Sturgeon, even if there is a possibility of our moral theory being wrong, this does not mean that we should think our moral theory is generally mistaken and we should still think that our moral theory is "roughly correct". ${ }^{38}$ There is no reason, according to Sturgeon, to doubt our moral theory so much as to think that it is completely wrong. ${ }^{39}$ So, we can use our moral theory to make judgments about events and people's characters.

Sturgeon is reacting to Harman, and this difference of interpretation over particular details within the moral realism and moral anti-realism debate emphasizes the discord throughout realism and anti-realism more generally. There

\footnotetext{
35 Ibid, 236.

36 Ibid, 243.

37 Ibid, 251.

38 Ibid, 253.

39 Ibid, 253.
} 
seems to be little agreement even on which features are realist and which features are anti-realist. This has encouraged a number of philosophers to attempt to create a meta-physical theory, or a metaphysical theory concerning morality or moral claims (i.e. a metaethical theory), that attempts to solve the apparently irreconcilable arguments between realism and anti-realism. One of these attempts is Simon Blackburn's quasi-realism.

\subsection{Quasi-Realism}

Before outlining Blackburn's quasi-realism, I would like to make his metaphysical position on the nature of ethics (or moral facts, claims, etc.) more clear. Blackburn says of his own theory,

This theory is visibly anti-realist, for the explanations offered make no irreducible or essential appeal to the existence of moral 'properties' or 'facts'; they demand no 'ontology' of morals. They explain the activity from the inside out-from the naturally explicable attitudes to the forms of speech that communicate them, challenge them, refine them, and abandon them, and which so mislead the unwary. 40

Blackburn is an anti-realist about ethics—so though he calls his view quasi-realism, he is not a realist. And, while his theory is different from other anti-realist theories, it is not an alternative to the traditional moral realism and moral anti-realism debate. ${ }^{41}$ He uses aspects of realism in an internal (to use Carnapian language) ${ }^{42}$ way, and this is why he coins his view quasi-realism (the Collins Pocket Reference English Dictionary, Canadian Edition defines quasi as "seemingly, resembling but not

${ }^{40}$ Simon Blackburn, "How To Be an Ethical Anti-Realist," in Essays in Quasi-Realism (Oxford: Oxford University Press, 1993), 175-176.

${ }^{41}$ I would like to clarify that my standard for an alternative option needs to be either outside of moral realism and moral anti-realism, or needs to not partake in the moral realism and moral anti-realism debate.

42 This will become apparent in the next section, 1.5, on Rudolf Carnap's paper "Empiricism, Semantics, and Ontology." 
actually being"43). But, he does not think that there are moral facts that exist in the world (completely mind-independently or objectively in the sense of ShaferLandau's "stance-independence"). He thinks that moral facts, or claims, are minddependent to an extent (which is seemingly an anti-realist position on the ontology of moral facts).

Connecting this back to the definitions of moral realism and moral antirealism will make Blackburn's position more explicit. The moral realist believes that there are moral facts, and that these moral facts can be verified as true or false (in some objective or "stance-independent" way). Traditionally, moral anti-realism denies the moral realist view in some way (for example, they can deny that moral facts can be verified as true or false). Blackburn's quasi-realism does not deny that moral facts can be true or false, but it does deny that moral facts are objective in either a mind-independent or "stance-independent" way.

On p. 169, of his paper “How To Be An Ethical Anti-Realist," Blackburn gives the following example,

We can sum up this contrast [between spatial perception and ethical stances] by saying that although the teleology of spatial perception is spatial, the teleology of ethical commitment is not ethical. The good of spatial perception is to be representative, but the good of ethical stances is not. ${ }^{44}$

Blackburn is demonstrating the contrast that, though he thinks that spatial perception corresponds to something that exists in the world, he does not think that moral facts (or claims, or stances) correspond to something that exists in the world.

${ }^{43}$ Collins Pocket Reference English Dictionary, Canadian Edition, s.v. "quasi." ${ }^{44}$ Blackburn, "How To Be an Ethical Anti-Realist," 169. 
He is "visibly" an anti-realist when it comes to moral facts, because he thinks moral facts are mind-dependent.

Blackburn goes on to explain a moral realist position he associates with John McDowell and David Wiggins. He says that their position has some similarities to his own projectivism (quasi-realism), but that they differ in that McDowell and Wiggins think "that sentiments have something to do with our capacity to make ethical judgements," and "yet [want] to retain a 'perceptual' and cognitive place for moral opinion." ${ }^{45}$ This ties into Blackburn's talk about spatial perception being for spatial representation in the 'real' world, while ethical stances are not for ethical representation in the 'real' world (i.e. they do not represent something tangible in the world outside of the mind).

Blackburn founds his moral anti-realist view, quasi-realism, on a kind of naturalism and on projectivism. His naturalism being what I would have attributed to empiricism: everything can be explained through science (i.e. the natural, physical world). His projectivism is more complicated. Blackburn thinks that "a 'projective' theory can be developed to give a satisfying way of placing our propensities for values." 46 He does not go into very much detail by what he means by "'projective' theory," but, from the rest of the paper, I think he means that human beings have natural (referring back to the naturalism) reactions and that these reactions are attitudes (or attributes, or emotions). These attitudes towards (or against)

\footnotetext{
45 Ibid, 170.

${ }^{46}$ Ibid, 167.
} 
something are natural and ethical. They are the precursor to rational reflection (i.e. what we base our rational reflection on).

Therefore, Blackburn is an anti-realist, but not a relativist. He's an antirealist, because he thinks moral facts (or moral propositions, claims, etc.) are our attitudes (not some proposition that exists independent of the mind). He's not a relativist, in part, due to his naturalism. From what I take his position to be, he thinks that we have natural reactions (or verdicts) to things and this is necessarily so. He says, in support of my understanding in the previous sentence, "The existence of the verdict, of course, depends on the existence of those capable of making it [...]." ${ }^{47}$ He goes on to use Humean metaphysics to underpin this natural necessitynatural necessity is natural regularity based on our forming of dispositions towards expectation. $^{48}$

While Blackburn uses naturalism as part of his quasi-realism, it is not meant, at least not in "How To Be an Ethical Anti-Realist", to mean that our language is reducible to or directly descriptive of the natural state of physical affairs. Blackburn's naturalism is to ground that humans have evolved to have certain moral reactions or attributes. Moral facts, for Blackburn, require the further step of reflecting on these moral reactions and attributes, and so are not necessarily descriptive of the physical state of affairs in the world. The further condition of quasi-realism, projectivism, adds that we then project our moral reactions (or attributes) onto the world making them contingent on us (human beings), and attributes of the Real world.

47 Ibid, 178.

48 Ibid, 179. 
In an effort to be charitable to quasi-realism and differentiate it from moral realism and moral anti-realism — and probably explain partly how it got its namequasi-realism draws on parts of both of Sayre-McCord's definitions, which I think emphasizes that there is something off about the traditional moral realism and antirealism debate. The views have traditionally been split, but Blackburn's quasirealism highlights that this is problematic. Quasi-realism abides by these aspects of moral realism: “(1) the claims in question, when literally construed, are literally true or false (cognitivism), and (2) some are literally true." ${ }^{49}$ But, it is also contingent on human beings and our natural evolutionary biological reactions to things, and "embrace[s] a non-cognitivist analysis of the claims in question"50 making it very much an anti-realist theory. Quasi-realism incorporating aspects of both moral realism and moral anti-realism may seem contradictory, but it is not. It is a moral anti-realist theory on its foundation, but then develops an internal (or epistemological or cognitive) theory that resembles realism after we reflect on our moral reactions and make our moral reactions into moral facts (or claims).

Perhaps quasi-realism highlights that the traditional moral realist and moral anti-realist debate has failed to capture what is really going on when we make moral claims. It might not matter what our beliefs are on the metaphysical level of realism and anti-realism. What matters is what we can show on an internal (or epistemological) level that it is here that we can see whether a moral claim is true or false-it is here that moral claims get their meaning.

\footnotetext{
${ }^{49}$ Sayre-McCord, Essays on Moral Realism, 5.
} ${ }^{50}$ Ibid, 5. 


\section{5. "Empiricism, Semantics, and Ontology" by Rudolf Carnap}

The problem may just be that we cannot adequately capture what is going on in any realism and anti-realism debate (including the moral realism and moral antirealism debate). This apparent stalemate does not mean that the debate has to end here. There are other ways of approaching the debate that may help further it. While Rudolf Carnap was an anti-realist, he provided a theory of linguist frameworks that could very well help.

Carnap, in his paper "Empiricism, Semantics, and Ontology" says,

[...] [W] must distinguish two kinds of questions of existence: first, questions of the existence of certain entities [...] within the framework; we call them internal questions; and second, questions concerning the existence or reality of the system of entities as a whole, called external questions. ${ }^{51}$

The first question Carnap articulates in this quote is concerning "the existence of certain entities" within a linguistic framework: "internal questions". Internal questions are questions that are epistemological in nature, or questions about what we can know from within a given framework. The second question Carnap articulates is "concerning the existence or the reality of the system of entities as a whole": "external questions". External questions are questions that are ontological in nature, and are not questions about what we can know from within a given framework - they are questions that are asked from outside of the framework.

Carnap's main project in this paper is to show that through using a language framework (bracketed from any ontological statements about reality ${ }^{52}$ ) we can

${ }^{51}$ Rudolf Carnap, "Empiricism, Semantics, and Ontology," in Meaning and Necessity: A Study in Semantics and Modal Logic, Second Edition (Chicago: The University of Chicago Press, 1956), 206.

52 Bracketed from any statements about the Real world. 
avoid the issue that arises for some anti-realists (or empiricists in Carnap's language, since he associates empiricism with anti-realism/nominalism) when using “certain expressions in a language... [to] designate (or name or denote or signify or refer to) certain extra-linguistic entities." 53 The issue arises for anti-realists when these "extra-linguistic entities" are abstract entities, because they deny that these expressions in language (such as the adjective "red" or the number "five") refer to a real entity in the world. ${ }^{54}$

Carnap builds his framework through using examples of different languages of abstract entities (such as the languages of "The world of things" and "The system of numbers"). He is trying to show that we can still speak meaningfully about abstract entities when we ask questions about them of what he calls an "internal" nature-to be differentiated from questions of an external nature. ${ }^{55}$ As a reminder: internal questions are "questions of the existence of certain entities [...] within the framework," while external questions are "questions concerning the existence or reality of the system of entities as a whole." 56

I think Carnap's internal framework theory in "Empiricism, Semantics, and Ontology" shows that we can still have internal philosophy without having to state anything about metaphysics. While Carnap's paper is helpful for the anti-realist, it is also helpful for the sceptic concerning the ontological status of abstract entities (including moral facts). Though, Carnap's internal framework theory is not actually problematic for the realist, because internal frameworks do not assert anything

${ }^{53}$ Carnap, "Empiricism, Semantics, and Ontology," 216.

${ }^{54}$ Ibid.

55 Ibid, 206.

56 Ibid. 
about the Real world (or, in Carnap's language, "the world of things"57). So, it seems possible for internal questions to be asked without having to ask external questions, which means that we can know things on an internal level within a given framework-without running into the problem of not being able to properly capture what is going on in any realism and anti-realism debate (including the moral realism and moral anti-realism debate) due to the external nature of the questions within the realism and anti-realism debate.

\subsection{Pyrrhonian, Academic, or Methodological Scepticism?}

In the Outlines of Pyrrhonism by Sextus Empiricus, he states that there are three "natural [results] of any investigation" and those results are the following three positions: "Dogmatic," "Academic," and "Sceptic."58 The "Dogmatists," according to Sextus Empiricus, "specially so called-Aristotle, for example, and Epicurus and The Stoics and certain others;" think that they have "[discovered] the object of [their] search."59 The "Academics," such as "Cleitomachus and Carneades," "deny that [the object of their investigation] is discoverable and confess it to be inapprehensible." 60 And, "the Sceptics keep on searching"61—the Sceptics also remain agnostic (epochē) in their searching.

Neil Gascoigne explains in his book Scepticism,

For Sextus, the Dogmatist and the Academic present mirror images of each other: where one asserts that knowledge is possible (that things can be apprehended), the other denies it. To put this more precisely, the Dogmatist

57 Ibid.

58 Sextus Empiricus, Outlines of Pyrrhonism, trans. R. G. Bury (Cambridge, Massachusetts: Loeb Classical Library, 1933), 1.1-1.4.

59 Ibid.

60 Ibid.

61 Ibid. 
assumes that we can have the philosophical knowledge that shows that knowledge is possible. Equally, the Academic assumes that we can have the philosophical knowledge that shows that knowledge is not possible. ${ }^{62}$

The idea is that for Sextus Empiricus, both the Dogmatist and the Academic are dogmatic, because they do no remain agnostic and both assert their positions to be true. The Sceptic cannot assert that their position is true, but can say that they do not know whether the Dogmatic position or the Academic position is true or false. As Gascoigne goes on to say,

However the Sceptic comes to the view that he must go along with appearances in order to achieve happiness, it cannot be on the basis of a claim to [...] know what things are really like (in their essential nature). ${ }^{63}$

That is, that though the Sceptic goes along with appearances, ${ }^{64}$ their going along with appearances cannot be founded on any claims to know what the Real world is really like.

Gascoigne further distinguishes between Pyrrhonian Scepticism and Academic Scepticism. According to Gascoigne, Arcesilaus founded Academic Scepticism, around 270 BCE, when he was Head of the Academy-around 75 years after Plato's death. ${ }^{65}$ Arcesilaus thought that both Stoicism and Epicureanism (prominent schools of philosophy in Ancient Greece) were "Dogmatic perversions of the Socratic legacy;"66 and so forwarded 1) "that he knew nothing", and 2) his method "[suggested] a link between the 'way' in which Socrates arrived at his 'admission of ignorance' and Arcesilaus's explicit engagement with the opinions of

62 Neil Gascoigne, Scepticism, in Central Problems of Philosophy, ed. John Shand (Montreal and Kingston: McGill-Queen's University Press, 2002), 33.

63 Ibid, 41.

${ }^{64}$ Or, perceptions.

${ }^{65}$ Gascoigne, Scepticism, 41.

${ }^{66} \mathrm{Ibid}, 42$. 
the Dogmatists of his own time." ${ }^{67}$ Arcesilaus' method is similar to Socrates' method in Plato's dialogues. ${ }^{68}$ The method Plato details: Socrates goes around asking people what they know, and through a series of questions shows the people he asks that they actually know nothing. The goal being to show that to only know that you know nothing is better than thinking you know something when you do not. ${ }^{69}$

But, this gets back to what Sextus Empiricus said about the Academics in the Outlines of Pyrrhonism: they "deny that [the object of their investigation] is discoverable and confess it to be inapprehensible." ${ }^{70}$ Academic Sceptics deny that they know anything (concerning the Real world). This seems to be still dogmatic, even if Arcesilaus took issue with the Dogmatists, and Sextus Empiricus is right that Academic Scepticism is the flipside or "mirror" (as Gascoigne says) of Dogmatism. Therefore, to use more contemporary language, it seems like the Dogmatists are realists, the Academics are anti-realists, and the Sceptics are actual agnostic sceptics. Using Academic Scepticism as a tool is what turns into the 'Method of Doubt', which gets associated with René Descartes (specifically his First and Second Meditations in his Meditations on First Philosophy) in the Early Modern period. Simon Blackburn says, of the Method of Doubt, in the Oxford Dictionary of Philosophy, "It attempts to put knowledge upon a secure foundation by first inviting us to suspend judgement on any proposition whose truth can be doubted, even as a

${ }^{67} \mathrm{Ibid}, 43$.

68 Ibid.

69 'To know' meaning to know something about the Real world.

${ }^{70}$ Sextus Empiricus, Outlines of Pyrrhonism, 1.1. 
bare possibility." 71 The Method of Doubt is to question anything you think you know to get rid of beliefs founded on a false foundation. But, Descartes arguably does not actually doubt that the extended, or Real, world exists. He says in the Sixth Meditation,

[0]n the one hand I have a clear and distinct idea of myself, in so far as I am simply a thinking, non-extended thing; and on the other hand I have a distinct idea of body, in so far as this is simply an extended, non-thinking thing. [...]

Of course I also recognize that there are other faculties (like those of changing position, of taking on various shapes, and so on) which, like sensory perception and imagination, cannot be understood apart from some substance for them to inhere in, and hence cannot exist without it. But it is clear that these other faculties, if they exist, must be in a corporeal or extended substance and not an intellectual one; for the clear and distinct conception of them includes extension $[\ldots]]^{72}$

This seems to indicate that Descartes was not an Academic Sceptic or a Pyrrhonian Sceptic. He did think he could know something about the Real (i.e. extended) world, and did not remain agnostic either. For this reason, the Academic heritage that Descartes relies on in the Method of Doubt is only used as a tool, and not used seriously. Due to it only being used instrumentally, or as a "method", I call Descartes' utilization of scepticism 'Methodological Scepticism' rather than Academic, or agnostic/Pyrrhonian Scepticism.

There then seems to be three different types of scepticism that we can distinguish between: Pyrrhonian (or agnostic) Scepticism, Academic Scepticism, and Methodological Scepticism. I have already explained how Methodological Scepticism differs from Pyrrhonian Scepticism and Academic Scepticism, but it would be a good

${ }^{71}$ Simon Blackburn, "method of doubt," in the Oxford Dictionary of Philosophy, Third Edition (Oxford: Oxford University Press, 2016), 304.

${ }^{72}$ René Descartes, Meditations in First Philosophy, in The Philosophical Writings of Descartes, Volume II, trans. John Cottingham, Robert Stoothoff, and Dugald Murdoch (Cambridge: Cambridge University Press, 1984), 54-55. 
idea to make the distinction between Pyrrhonian Scepticism and Academic Scepticism a little more clear. In Book I, Chapter XXXIII—“Wherein Scepticism differs from the Academic Philosophy" in Outlines of Pyrrhonism, Sextus Empiricus explains how Pyrrhonian Scepticism differs from Academic Scepticism. At 1.223, Sextus Empiricus says,

And if Plato [from the first of, potentially, five schools of Academic Scepticism] does really utter some statements in a sceptical way when he is, as they say, "exercising," that will not make him a Sceptic; for the man that dogmatizes about a single thing, or ever prefers one impression to another in point of credibility or incredibility, or makes any assertion about any non-evident object, assumes the dogmatic character $[\ldots ..] .^{73}$

In Book I, Chapter XXXIII; Sextus Empiricus lists three main schools of Academic Scepticism, and lists two more schools that he also thinks should be included. ${ }^{74} \mathrm{He}$ goes through explaining how the five different schools of Academic Scepticism are not Pyrrhonian Scepticism, but the above quote attacking Plato's (or Socrates') 'scepticism' gets to the heart of the distinction between Academic Scepticism and Pyrrhonian Scepticism.

Even Academic Sceptics like Arcesilaus, end up making a claim: "all things are non-apprehensible"75 (i.e. that all things are not knowable). The problem with this, Sextus Empiricus says, is that "[Academics] affirm [that all things are nonapprehensible] positively, whereas the Sceptic regards it as possible that some things may be apprehended." ${ }^{\prime 6}$ As soon as the Academic Sceptic affirms that they know nothing, they are making an assertion about something (in a way that entails

\footnotetext{
73 Sextus Empiricus, Outlines of Pyrrhonism, 1. 223.

74 Ibid, 1.220-221.

75 Ibid, 1.226.

76 Ibid.
} 
that they do know something: that they know nothing), and this is dogmatic and not actually Scepticism according to Sextus Empiricus.

One last major difference between Academic Scepticism and Pyrrhonian Scepticism is that for the Pyrrhonians, agnosticism, or the suspension of judgement (epochē), is what leads to tranquillity of mind (ataraxia) and the good life (eudaimonia). Richard H. Popkin and José R. Maia Neto say in the introduction to their anthology Skepticism: An Anthology, in regards to Pyrrhonian Scepticism,

The investigation does not end with the inquirer finding the truth (which is what the skeptics technically call "dogmatism"), but in a situation of equipollence between the doctrines or phenomena examined (that is, one doctrine does not appear as more credible than a conflicting one) and so, unable to assent to either of them, the Pyrrhonian suspends judgement (epoché). Contrary to the initial perspective of getting rid of the disturbance by finding truth, it is when the inquirer suspends judgement that he or she finds the tranquillity being sought.77

While the Academic Sceptic says that they abide by the suspension of judgement (epochē), their primary goal is to use the 'Socratic method' to get rid of false beliefs. The Pyrrhonian Sceptic's primary goal is tranquillity of mind (ataraxia).

To add to the complexity of the different types of scepticism, there is also something called Moderate Pyrrhonism. In his paper “Moderate Classy Pyrrhonian Moral Scepticism" and more elaborately in his book Moral Skepticisms, Walter Sinnott-Armstrong articulates a kind of Moderate Pyrrhonism (in a moral scepticism context). Sinnott-Armstrong says,

My scepticism is also moderate. I suspend belief only about whether anyone is justified without qualification. This suspension is compatible with relativized epistemic judgements, such as that Sue is justified in believing that her pet is a dog as apposed to a cat, and that she is not justified in believing that her pet is a

77 Richard H. Popkin and José R. Maia Neto, eds., Skepticism: An Anthology (Amherst, New York: Prometheus Books, 2007), 22-23. 
dog as opposed to a dingo or hyena. ${ }^{78}$

Sinnott-Armstrong's Moderate Pyrrhonism reins in the universal aspect of Pyrrhonism. It still remains agnostic when it comes to judgements that are not “justified without qualification," but "relativized epistemic judgements" can still be made on this view.

I think it is important to now give a general, contemporary definition of scepticism, and analyse it. Part of Blackburn's definition of scepticism in the Oxford Dictionary of Philosophy states,

Although Greek scepticism centred on the value of enquiry and questioning, scepticism is now the denial that knowledge or even rational belief is possible, either about some specific subject matter (e.g. ethics) or in any area whatsoever. ${ }^{79}$

This part of Blackburn's definition seems to be heavily biased towards Academic Scepticism. If you continue reading the definition Blackburn gives, it seems at times that he actually conflates Pyrrhonian Scepticism with Academic Scepticism. There seems to be a lot of confusion over the different types of scepticism in contemporary philosophy, and I think a lot of this is due to conflating the different types of scepticism. It should be noted that Pyrrhonian (or agnostic) Scepticism is not Academic Scepticism, and Pyrrhonian Scepticism and Academic Scepticism are both not Methodological Scepticism. The use of scepticism as a tool in philosophy (i.e. Methodological Scepticism) — since the Early Modern period to present day-has also been conflated with both Pyrrhonian Scepticism, or what I like to think of as

78 Walter Sinnott-Armstrong, "Moderate Classy Pyrrhonian Moral Scepticism," The Philosophical Quarterly 58, no. 232 (July 2008): 454.

${ }^{79}$ Simon Blackburn, "scepticism," in the Oxford Dictionary of Philosophy, Third Edition (Oxford: Oxford University Press, 2016), 429. 
'actual' agnostic scepticism, and Academic Scepticism. I find this problematic, especially when trying to understand specific philosophies (like Kant's, or Hume's). I think it is important to keep in mind the problematic conflations of the different types of scepticism while reading allegedly 'sceptical' writings, and the criticisms of those writings, in order to decipher the writings that are actually sceptical and the criticisms that should be taken seriously.

\subsection{Naturalism}

Defining naturalism is a tricky endeavour (not unlike defining realism and anti-realism). The term 'naturalism' has been used in philosophy by many people supporting many different varieties of ideas and theories. As P. F. Strawson states at the beginning of Skepticism and Naturalism: Some Varieties,

The term "naturalism" is elastic in its use. The fact that it has been applied to the work of philosophers having as little in common as Hume and Spinoza is enough to suggest that there is a distinction to be drawn between varieties of naturalism. ${ }^{80}$

While Strawson goes on to distinguish between hard naturalism and soft naturalism, I would prefer to distinguish between Methodological Naturalism and Ontological Naturalism (sometimes also conjoined with Metaphysical Naturalism and referred to as Philosophical Naturalism).

To start, I will first outline Methodological Naturalism. Paul Kurtz, in his paper "Darwin re-crucified: why are so many afraid of naturalism," defines Methodological Naturalism as follows,

First, naturalism is committed to a methodological principle within the context of scientific enquiry; i.e., all hypotheses and events are to be explained and

${ }^{80}$ P. F. Strawson, Skepticism and Naturalism: Some Varieties, The Woodbridge Lectures 1983 (New York: Columbia University Press, 1985), 1. 
tested by reference to natural causes and events. To introduce a supernatural or transcendental cause within science is to depart from naturalistic explanations. On this ground, to invoke an intelligent designer or creator is inadmissible. 81

David Papineau, in the Stanford Encyclopedia of Philosophy article "Naturalism", more simply says, “Methodological naturalists see philosophy and science as engaged in essentially the same enterprise, pursuing similar ends and using similar methods." ${ }^{22}$ The idea being that Methodological Naturalism follows the same method as science: using natural explanation without appeal to anything supernatural (such God, for example).

Now, I will outline Ontological Naturalism. Papineau states, with regard to Ontological Naturalism,

A central thought in ontological naturalism is that all spatiotemporal entities must be identical to or metaphysically constituted by physical entities. Many ontological naturalists thus adopt a physicalist attitude to mental, biological and other such "special" subject matters. They hold that there is nothing more to the mental, biological and social realms than arrangements of physical entities. ${ }^{83}$

Adding to this, Kurtz says more broadly,

According to the naturalists, nature is best accounted for by reference to material principles, i.e., by mass and energy and physical chemical properties as encountered in diverse contexts of inquiry. ${ }^{84}$

${ }^{81}$ Paul Kurtz, "Darwin re-crucified: why are so many afraid of naturalism," Free Inquiry, Spring 1998, accessed April 22 nd, 2018 , Academic OneFile, http://link.gale group.com.proxy.library.carleton.ca/apps/doc/A20633103/AONE?u=ocul_carleton \&sid=AONE\&xid=e7e2f9f7.

82 David Papineau, "Naturalism", The Stanford Encyclopedia of Philosophy, ed. Edward N. Zalta (Winter 2016 Edition), accessed on April 22 ${ }^{\text {nd }}, 2018$, https://plato. stanford.edu/archives/win2016/entries/naturalism/. ${ }^{83}$ Ibid.

${ }^{84}$ Paul Kurtz, "Darwin re-crucified: why are so many afraid of naturalism." 
And, so, Methodological Naturalism states that it follows the same method as science, and Ontological Naturalism states that everything in the universe can be explained by "material principles," and is constituted of "physical entities."

Both realists and anti-realists can adopt Methodological Naturalism quite easily as it makes no ontological claims about the Real world-it makes explanatory claims. Where things get more challenging for the anti-realist is when it comes to Ontological Naturalism. Though, an anti-realist may not take issue with Ontological Naturalism for every domain. An anti-realist does not have to be an anti-realist when it comes to neurons firing explaining brain states, but they can be an antirealist about abstract entities such as moral facts (or claims)—as Harman is. ${ }^{85}$

But, I would like to go a step further and say that Ontological Naturalism does not have to entail an ontological commitment to attributing scientific explanations, like neurons firing explaining mental states, to the Real world. You can very well explain mental states by way of neurons firing, even if you are an agnostic sceptic, because the explanation you give can be based on appearances rather than on making a statement about the Real world. The sceptic can say, "It appears that neurons firing explain brain states as far as I can know." This does not assert anything about the Real world, but rather makes a claim based on appearances allowing the sceptic to remain agnostic about the Real world. The sceptic cannot say that this is how the world is; they can only say that this is how the world appears. As quoted in section 1.6, in reference to Pyrrhonian Scepticism, "the Sceptic comes to

${ }^{85}$ Refer back to section 1.3 . 
the view that he must go along with appearances in order to achieve happiness."86 The sceptic still needs to live their life, and it is unrealistic for them to live not acknowledging anything. So, rather than make claims relating to the Real world, they make claims relating to appearances. ${ }^{87}$

In Section 2.2, that follows, nature is mentioned, "Nature has not left this to his choice, and has doubtless esteem'd it an affair of too great importance to be trusted to our uncertain reasonings and speculations." 88 Hume references nature countless times throughout A Treatise of Human Nature, and An Enquiry concerning Human Understanding. Hume's naturalism plays a role in how the rest of his philosophy is interpreted. One way of reading Hume as a realist is by using his naturalism to discredit, or reduce the power of, his scepticism. Another way of reading Hume is through accepting that he endorses both scepticism and naturalism, but that his philosophy is not cohesive at times. I think it is important to understand how Hume is using nature in order to understand what kind of naturalism arises in his philosophy in an effort to better understand the relationship between his scepticism and naturalism. I find that Hume uses nature in two ways: 1) to refer to human nature, and 2) to refer to our understanding of the rules of nature through our perceptions and experiences. The first use of nature is dependent on an understanding of the second use of nature.

\footnotetext{
86 Gascoigne, Scepticism, 41.

${ }^{87}$ Appearances are based on perceptions, and may, or may not, be accurate representations of the Real world-but the sceptic cannot make a claim about whether appearances are accurate representations of the Real world or not. 88 Treatise, 1.4 .2 .1 (p. 125).
} 
In the Treatise, Hume says, "We may draw inferences from the coherence of our perceptions, whether they be true or false; whether they represent nature justly, or be mere illusions of the senses." ${ }^{\prime 99}$ We make inferences via the knowledge we gain through our senses, and the implication here is that we cannot know whether our perceptions give us accurate knowledge of nature (in the Real, external world) or not. ${ }^{90}$ This is interesting given how frequently Hume falls back on nature in his explanations throughout both the Treatise and the First Enquiry. I will attempt to reconstruct Hume's understanding of nature in order to understand how it fits into Hume's philosophy as a whole.

To start with, Hume differentiates between "Relations of Ideas" and "Matters of Fact". ${ }^{91}$ Relations of Ideas "are the sciences of Geometry, Algebra, and Arithmetic; and in short, every affirmation, which is either intuitively or demonstratively certain." ${ }^{92}$ He gives examples of what he means by the relation of ideas, such as, "That three times five is equal to the half of thirty, expresses a relation between these numbers. ${ }^{\prime 93}$ Relations of ideas express a relationship between two ideas that we can know without having to rely on experience (perceiving something happen multiple times), and whose negation implies a contradiction.

\footnotetext{
${ }^{89}$ Ibid, 1.3.5.2 (p. 59).

90 It should be noted that even though we cannot know whether or not our perceptions give us accurate knowledge of a Real, external world or not; the coherence of our perceptions still allows us to make inferences, and assess the truth or falsity of perceptions.

91 Why I am beginning with this distinction will become more clear at the section progresses.

${ }^{92}$ First Enquiry, 4.1 (p. 18).

93 Ibid.
} 
Matters of fact, on the other hand, are not demonstrable ${ }^{94}$, and so something and its negation can both be true. The example Hume gives is that "the sun may not rise tomorrow", or that the sun will rise tomorrow. ${ }^{95}$ Both statements can potentially be true, and a contradiction cannot be derived. The other main feature of matters of fact is that "[a]ll reasonings concerning matter of fact seem to be founded on the relation of Cause and Effect." 96 Hume says that it is by this "relation [of cause and effect] alone we can go beyond the evidence of our memory and senses."97 Reasoning concerning the relation of cause and effect "arises entirely from experience."98 Hume goes on to make the even stronger claim "that causes and effects are discoverable, not by reason, but by experience." ${ }^{\prime 99}$ Hume, then, goes on to give a few examples. One of the examples he gives is of "the explosion of gunpowder."100 The idea being that you cannot know that gunpowder explodes prior to experience with it. ${ }^{101}$

I am not so much concerned with relations of ideas, but with matters of fact. Matters of fact are how we gain perceptual knowledge of the natural world (i.e.

\footnotetext{
${ }^{94}$ A logical proof cannot be given.

95 First Enquiry, 4.1 (p. 18).

96 Ibid, 4.4 (p. 19).

97 Ibid.

98 Ibid, 4.6 (p. 19).

99 Ibid, 4.7 (p. 20).

100 Ibid.

101 I mean, you can read about it in a book, but the person who wrote the book would need to have gained knowledge of gunpowder somehow and the way to do so would be to have experience with gunpowder. Though, I do think, for Hume, that reading that gunpowder explodes in the book is not exactly knowledge that gunpowder explodes. You would need direct experience with gunpowder, preferably multiple experiences with it.
} 
external world). ${ }^{102}$ So, it would appear that the naturalism found in Hume's

philosophy is one based on perceived experiential relations (such as cause and effect) rather than concrete knowledge, and therefore all you can have are natural relations (or rules or facts) that can only ever lead to probability and not certainty. This is a very different picture than some modern reductionist forms of naturalism where it is believed that nature (and the whole external world) is reducible to the smallest discoverable denomination in science (for example, quarks). For Hume, one can reduce nature to the smallest denomination discoverable in science, but this would all be conjecture-because it is based on experience (i.e. sense impressions/ perceptions combined with our experience of these sense impressions/perceptions) and has the potential to be true or false (we cannot know for sure the truth or falsity of something by attempting to reference it to the external world, we can only assess truth or falsity within a given framework). ${ }^{103}$

It is worth adding, given Hume's sceptical views concerning metaphysics, that we can never have access to the knowledge of what any ultimate causes or first principle(s) are, making nature always probable and not $100 \%$ certain,

Hence we may discover the reason, why no philosopher, who is rational and modest, has ever pretended to assign the ultimate cause of any natural operation, or show distinctly the action of that power, which produces any single effect in the universe. It is confessed, that the utmost effort of human reason is, to reduce the principles, productive of natural phaenomena, to a greater simplicity, and to resolve the many particular effects into general causes, by means of reasonings from analogy, experience, and observation. But

102 The content of our knowledge of the external world consists of perceptions. This means that we have no direct knowledge of the external world, we only have knowledge of our perceptions. Direct knowledge of the external world is not something we have access to for Hume.

${ }^{103}$ It does not give you the cognitivist requirement that we can know that at least some claims are true. 
as to the causes of these general causes, we should in vain attempt their discovery; nor shall we ever be able to satisfy ourselves, by any particular explanation of them. These ultimate springs and principles are totally shut up from human curiosity and enquiry. ${ }^{104}$

So, though we can reduce nature to general rules for greater simplicity through our experiences and observations, the ultimate causes and first principle(s) of nature can never be known to us (humans). This emphasizes that Real, external rules (or laws) of nature are not things that can be directly known. The rules, or laws, of nature that we can know through perception and experience are based on probability, not certainty. This then entails that Hume's naturalism is not based on asserting anything in the external world with certainty that can be known to be true-that is, Hume's naturalism is not a realist or cognitive assertion. Natural, or physical, objects that we become aware of via perception, the things we perceive in the world, cannot necessarily be equated with Real, external objects-we cannot know the connection between the object of our study (the physical object of our perception) and the Real, external object.

\subsection{Hume: Realist, Anti-Realist, or Sceptic?}

Different people have interpreted Hume as a realist, an anti-realist, or a sceptic in their efforts to understand his philosophy-there is no consensus as to which Hume actually was. Because there is no consensus in the literature, I will have to give my own interpretation of Hume with support in the following chapter. In this section, to show the lack of consensus, I will briefly give an account of each of the different interpretations of Hume. To start, I will look at Barry Stroud's realist interpretation of Hume. Secondly, I will look at Thomas Reid's anti-realist

${ }^{104}$ First Enquiry, 4.12 (p. 22). 
interpretation of Hume. And, thirdly, I will look at Robert J. Fogelin's sceptical interpretation of Hume.

While Barry Stroud does acknowledge Hume's sceptical passages, he thinks that Hume is ultimately a realist,

'Obstinate nature' can obliterate our sceptical doubts in a moment, and 'carelessness and in-attention' afford an easy remedy for our distress (p. 218). This is not to say that nature somehow refutes scepticism and shows that it is not true. Our natural instincts do not successfully meet or resolve the sceptical doubts; they simply submerge them. Man is so constituted that he must believe, for example, in the existence of bodies, even though he cannot defend that belief with any good reasons. Nor will any account of good reasoning free him from the sceptical doubts arising inevitably out of reflection on the grounds for that belief. But, we do get free from such doubts, nevertheless. ${ }^{105}$

Stroud then quotes Hume and carries on by saying,

We cannot avoid seeing the results of our philosophical reflection as artificial and contrived, and we will inevitably yield to nature and accept 'the general maxims of the world' (p. 269) despite a convincing philosophical demonstration of the unreasonableness, or even the falsity, of those beliefs. 106

According to Stroud's interpretation of Hume's philosophy, we cannot help but to fall into doubt when we reflect and philosophize, but, in the end, we revert back into a realist position as we "yield to nature". It is a realist interpretation of Hume, because, according to Stroud, Hume thinks that humans naturally think that bodies exist in the external world—not just the appearance of bodies in the external world, but Real, external bodies.

Thomas Reid, on the other hand, seems to have had an anti-realist interpretation of Hume's philosophy. Reid was a contemporary of Hume, and was highly critical of Hume's philosophy. Reid interpreted Hume as allowing his, meaning Hume's, philosophy to lead Hume "to disbelieve the existence both of

105 Barry Stroud, Hume (New York: Routledge \& Kegan Paul plc, 1977), 115. 106 Ibid, 116. 
matter and of mind."107 According to Reid, Hume denied that anything existed in the external world, which a Pyrrhonian Sceptic would call negatively dogmatic, Academic Scepticism, or anti-realism. ${ }^{108}$ To further elaborate, Reid says,

Mr HUME adopts LOCKE'S account of the origin of our ideas, ${ }^{109}$ and from that principle infers, that we have no idea of substance, corporeal or spiritual, no idea of power, no other idea of cause, but that it is something antecedent, and constantly conjoined to that which we call its effect; and, in a word, that we can have no idea of any thing but our sensations, and the operations of mind we are conscious of. 110

Again, Reid says that Hume negatively asserts that we have no idea of substance (this also means that we have no direct idea of the external world). Reid also says that Hume asserts that all we can have ideas of, knowledge of, are "our sensations, and the operations of mind we are conscious of" - this would mean that our ideas are mind-dependent. The combination of not having any idea of external substance and all our ideas being mind-dependent makes Reid's interpretation of Hume's philosophy an anti-realist interpretation.

Robert J. Fogelin articulates an interpretation of Hume as a true sceptic in his paper "The Skeptics Are Coming! The Skeptics Are Coming!”,

Hume, whom I take to be an urbane Pyrrhonian [Moderate Pyrrhonian Sceptic], explicitly makes this move [to show that the dogmatists' program, such as Academic Scepticism, "actually generates a radical skepticism rather than avoids it"] in the Treatise when he tells us: "It is impossible, upon any system, to defend either our understanding or senses; and we but expose them further when we endeavour to justify them in that manner. As the sceptical doubt arises naturally from a profound and intense reflection on those subjects, it

107 Thomas Reid, Essays on the Intellectual Powers of Man (Edinburgh: Printed for John Bell, Parliament Square, and G. G. J. \& J. Robinson, London, 1785), 187. 108 Reid is also taking issue with Hume's theory of mind in the previous quote, but I am focusing on Reid's interpretation of Hume's theory of perception and metaphysics.

${ }^{109}$ Reid says in the previous paragraph that the origin of ideas for Locke is sensation and reflection.

110 Reid, Essays on the Intellectual Powers of Man, 189. 
always increases the further we carry our reflections, whether in opposition or conformity to it." Since Hume held a rustic ${ }^{111}$ interpretation of ancient Pyrrhonism, he distanced himself from it in these words: "But a Pyrrhonian cannot expect, that his philosophy will have any constant influence on the mind: or if it had, that its influence would be beneficial to society. On the contrary, he must acknowledge, if he will acknowledge any thing, that all human life must perish, were his principles universally and steadily to prevail. All discourse, all action would immediately cease; and men remain in a total lethargy, till the necessities of nature, unsatisfied, put an end to their miserable existence." Taking it as rustic, Hume recommends a philosophical tonic containing "only a small tincture of Pyrrhonism." If he had interpreted Pyrrhonism as urbane, he could have counseled a full quaff of the real stuff. 112

Fogelin's interpretation of Hume's philosophy in the above quote understands Hume as mitigated, or moderate, Pyrrhonian Sceptic — the kind that assents to appearances, but remains agnostic about the metaphysical status of facts, objects, etc., in the external, Real world. Hume is not a radical Pyrrhonian Sceptic, according to Fogelin, and it is precisely radical Pyrrhonian Scepticism that Hume speaks against. But, to be a Pyrrhonian Sceptic, Hume need not be radical in his views. He can accept a mitigated Pyrrhonian Scepticism, or Moderate Pyrrhonian Scepticism, and still be a true sceptic (in the Ancient Greek understanding of scepticism as withholding judgement, epochēe.

\subsection{An Interpretation of Hume's Philosophy}

I do think that Hume's scepticism and naturalism are cohesive, ${ }^{113}$ and that his moral philosophy is also cohesive. Not only that, but that Hume's philosophy is cohesive across his scepticism, naturalism, and moral philosophy. In this section, I

111 "Treated as rustic, the Pyrrhonist is pictured as setting aside subtlety and flatfootedly seeking suspension of belief on all matters whatsoever, including the practical beliefs concerning everyday life." Robert J. Fogelin, "The Skeptics Are Coming! The Skeptics Are Coming!," in Pyrrhonian Skepticism, ed. Walter SinnottArmstrong (Oxford: Oxford University Press, 2004), 163.

112 Ibid, 164.

113 By cohesive I mean consistent and mutually supporting, and not resulting in a contradiction or incompatibility. 
will be primarily using secondary support from Don Garrett to help show that these components of Hume's philosophy are cohesive. I will first look at a paper by Don Garrett called “'A Small Tincture of Pyrrhonism': Skepticism and Naturalism in Hume's Science of Man" (with some reference to Robert J. Fogelin's paper "The Skeptics Are Coming! The Skeptics Are Coming!") before turning to Chapter 9: "Moral Evaluation" in Garrett's book Cognition and Commitment in Hume's Philosophy. After considering “'A Small Tincture of Pyrrhonism': Skepticism and Naturalism in Hume's Science of Man" and "Moral Evaluation", I will show the connections between them with the goal being to demonstrate that Hume's philosophy is cohesive across his scepticism, naturalism, and moral philosophy. In the first paper I referred to, Garrett says—at the very end of his introduction-"Hume's naturalism and his skepticism are mutually supporting."114 It is his goal in this paper to show that Hume's naturalism and scepticism are not inconsistent. Garrett's alternative goal is to show that you do not have to support one at the expense of the other-for example, you do not have to hold that Hume is actually a naturalist at the expense of his scepticism; both naturalism and scepticism can hold simultaneously. ${ }^{115}$ After his introduction, Garrett explains a classification system of scepticism. Using Robert J. Fogelin's classification of scepticism to start

\footnotetext{
114 Don Garrett, "'A Small Tincture of Pyrrhonism': Skepticism and Naturalism in Hume's Science of Man," in Pyrrhonian Skepticism, ed. Walter Sinnott-Armstrong (Oxford: Oxford University Press, 2004), 69.

115 Once it is established that Hume's scepticism and naturalism are cohesive, I will then show that his scepticism and naturalism are also consistent with his moral philosophy. I start with supporting Hume's scepticism and naturalism first, because they inform his moral philosophy.
} 
with, Garrett discusses "six different dimensions" that scepticism can be broken

down into: domain, character, object, origin, degree, and persistence. ${ }^{116}$

Garrett defines Fogelin's "six different dimensions" of scepticism as follows.

Of domain Garrett says,

[T] he sets of propositions toward which [varieties of skepticism] are directed. The domain of a given instance of skepticism may be either general or limited. General skepticism concerns all propositions whatsoever; limited skepticism is directed only toward propositions of a particular subject matter or other kind. 117

Garret defines character, as he says Fogelin defines it, by splitting it into three subcategories,

[Character] may be theoretical, prescriptive, or practicing. Theoretical skepticism is a positive stance toward the view that that there is a lack of "rational grounds, warrant, or justification" for assenting to the propositions of a specified domain. Prescriptive skepticism is a positive stance towards the view that one ought not to assent-typically issuing in a recommendation to resist or refrain from assent- to the propositions of a specified domain. Practicing skepticism is a stance of actual doubting, or refraining from assent to, the propositions of a specified domain. ${ }^{118}$

He then says that object can "be either epistemological or conceptual,"

[E]pistemological skepticism does not concern the intelligibility of a domain of propositions but only the basis for assenting to propositions within it, whereas conceptual skepticism concerns the very intelligibility of a domain of propositions. ${ }^{119}$

After object, Garrett says that origin is "either antecedent or consequent,"

The distinction between antecedent and consequent skepticism is one of two distinctions that Hume himself draws and emphasizes in section 12 of $A n$ Enquiry Concerning Human Understanding. As Hume explains it, the former is "a species of scepticism, antecedent to all study and philosophy, which...recommends an universal doubt, not only of all our former opinions and principles, but also of our very faculties" (EHU 12.3). He contrasts this with

116 Garrett, “'A Small Tincture of Pyrrhonism': Skepticism and Naturalism in Hume's Science of Man," 69.

117 Ibid, 69-70.

118 Ibid, 70.

119 Ibid, 71. 
"another species of skepticism, consequent to science and enquiry, when men are supposed to have discovered either the absolute fallaciousness of their mental faculties or their unfitness to reach any fixed determination in all those curious subjects of speculation, about which they are commonly employed" (EHU 12.5). ${ }^{120}$

The second to last dimension, or differentiation, is degree. Degree can "be either unmitigated or mitigated,"

For example, an unmitigated theoretical skepticism about a domain embodies the view that assent to any proposition within it is utterly without rational ground, warrant, or justification; a mitigated theoretical skepticism embodies only the view that the rational ground, warrant, or justification of assent to such propositions is limited, or minimal, or less than generally supposed, or less than desirable, or otherwise falls below some specified or implied standard.121

And, finally, Garratt says of Fogelin's dimension of persistence,

[T] he persistence of skepticism may be either constant or variable. It is constant if the skeptic maintains the same degree of skepticism through time and reflection; it is variable if the degree of skepticism increases or decreases with changes in the skeptic's perspective or focus of attention. ${ }^{122}$

Garrett uses these "six different dimensions" to dissect Hume's scepticism in order to classify it (via how he understands Hume's scepticism). Though, Garrett is not completely satisfied with Fogelin's initial six differentiations, and to them he figures in two more forms of scepticism that are meant to replace what Fogelin calls "theoretical skepticism"-which falls under the character dimension of scepticism. These two new differentiations are "rational support skepticism" and "epistemic merit skepticism".123 Garrett defines "rational support skepticism" as "the view that assent to propositions in a given domain will lack rational support."124,125 And,

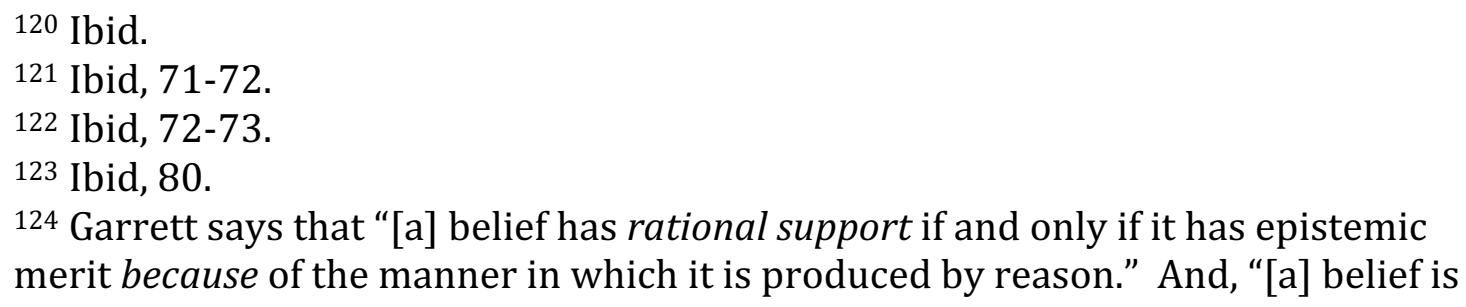


"epistemic merit skepticism [...] is the view that assent to propositions in a given domain will lack epistemic merit."126,127

He replaces theoretical scepticism with his distinction between these two new categories in an effort to support his conclusion. Garrett concludes at the end of “'A Small Tincture of Pyrrhonism"”,

Thus, naturalism leads naturally to a crisis of unmitigated practicing sceptical doubt, and the psychological defeat of that unmitigated practicing doubt incorporates the adoption of the only principle of epistemic merit that can now sustain a return to naturalism. This return to naturalism can occur, however, only in conjunction with a prescriptive and epistemic merit skepticism that is both constant and general-but mitigated.128

Leading up to the above quote, Garrett writes, “Hume's procedure is naturalistic from the start [...] [and] a mitigated and limited endorsement of [Hume's] own reliance on reason and the senses, an endorsement that can withstand his awareness of the many limitations of human cognitive nature [is] discovered."129 Though, this "mitigated and limited endorsement" is qualified by the limited nature of human cognition, which naturally leads to doubt (by which I mean scepticism). Interestingly, Hume does not identify himself as a moderate or mitigated Pyrrhonian Sceptic as Garrett's diagnosis of Hume's scepticism as "a prescriptive and epistemic merit scepticism that is both constant and general—but mitigated"

produced by reason if and only if it results from an operation of the inferential faculty [the ability for rational inference]." Ibid.

125 Ibid.

126 Garrett says that "[a] belief has epistemic merit if and only if it deserves or is worthy of belief or assent." Ibid.

127 Ibid.

128 Ibid, 90.

129 Ibid. 
would imply that Hume was. Though, Garrett and Fogelin both agree that Hume

may not have had extensive knowledge in ancient forms of scepticism. Garret says,

Hume recognizes two ancient sceptical schools: Pyrrhonian skepticism and Academic skepticism. As Julia Annas has recently argued, Hume does not exhibit, and evidently did not possess, deep historical knowledge of these two schools. ${ }^{130}$

So, while Hume knew that there were two Ancient Greek schools of scepticism, he did not know the differentiating factors between them.

As Fogelin emphasizes in his paper "The Skeptics Are Coming! The Skeptics

Are Coming!",

Hume, whom I take to be an urbane Pyrrhonian [Moderate Pyrrhonian Sceptic], explicitly makes this move [to show that the dogmatists' program, such as Academic Scepticism, "actually generates a radical skepticism rather than avoids it"] in the Treatise when he tells us: "It is impossible, upon any system, to defend either our understanding or senses; and we but expose them further when we endeavour to justify them in that manner. As the sceptical doubt arises naturally from a profound and intense reflection on those subjects, it always increases the further we carry our reflections, whether in opposition or conformity to it." Since Hume held a rustic 131 interpretation of ancient Pyrrhonism, he distanced himself from it in these words: "But a Pyrrhonian cannot expect, that his philosophy will have any constant influence on the mind: or if it had, that its influence would be beneficial to society. On the contrary, he must acknowledge, if he will acknowledge any thing, that all human life must parish, were his principles universally and steadily to prevail. All discourse, all action would immediately cease; and men remain in a total lethargy, till the necessities of nature, unsatisfied, put an end to their miserable existence." Taking it as rustic, Hume recommends a philosophical tonic containing "only a small tincture of Pyrrhonism." If he had interpreted Pyrrhonism as urbane, he could have counseled a full quaff of the real stuff. ${ }^{132}$

130 Ibid, 77.

131 "Treated as rustic, the Pyrrhonist is pictured as setting aside subtlety and flatfootedly seeking suspension of belief on all matters whatsoever, including the practical beliefs concerning everyday life.” Robert J. Fogelin, "The Skeptics Are Coming! The Skeptics Are Coming!," in Pyrrhonian Skepticism, ed. Walter SinnottArmstrong (Oxford: Oxford University Press, 2004), 163.

132 Ibid, 164. 
Hume's apprehension of Pyrrhonism comes down to him not having a thorough understanding of Ancient Scepticism, and, though, he denies being a Pyrrhonian, he is a Moderate Pyrrhonian Sceptic. And, Moderate Pyrrhonian Scepticism is compatible with Hume's "science of man" (naturalism). ${ }^{133}$ I invite you to think back to Garrett's argument that Hume's scepticism and naturalism are compatible at this point.

Garrett articulates-in more words than necessary—that Hume espouses a kind of mitigated, or moderate, form of Pyrrhonian Scepticism. And, this mitigated Pyrrhonism is compatible with "[t]he naturalistic cognitive and conative psychology that constitutes what Hume calls "the science of man", because "the science of man"

is an investigation of the operations of human faculties, which faculties include (among others) imagination, memory, the senses, the passions, the moral sense-and reason. It is often claimed that Hume uses the term "reason" in many different senses. In fact, however, he consistently uses it in a single sense-as a term in cognitive psychology designating the faculty of making inferences and engaging in argument.134

Hume's scepticism and naturalism are interconnected, and reliant on each other. This gives Hume the added bonus that his scepticism does not eliminate reason (or rational inference) due to his naturalism (which entails the cognitive psychology of humans). ${ }^{135}$

${ }^{133}$ Hume's "science of man" (naturalism) can be defined just as "the program of providing causal explanations for mental and other phenomena." Garrett, "A Small Tincture of Pyrrhonism," 68.

134 Ibid, 79.

135 The cognitive psychology of humans is the mental ability of humans to have access to certain knowledge. This harkens back to the Carnapian understanding of internal in that we can only ask certain kinds of questions because we only have access to certain kinds of answers-in the case of humans, we can only have access to internal questions and can only give internal answers. 
Hume's scepticism and naturalism are interconnected, but what about his moral philosophy? At this stage in the section, I think it would be a good idea to switch over to Chapter 9: "Moral Evaluations" in Don Garrett's book Cognition and Commitment in Hume's Philosophy. Garrett starts the chapter by distinguishing between two competing interpretations of Hume's moral philosophy (focusing on moral evaluations). One interpretation, Garrett calls "nonpropositional theories", and the other interpretation he calls "propositional theories". ${ }^{136,137}$ Of the nonpropositional and propositional distinction, Garrett writes,

[The] question is whether moral evaluations do or do not affirm genuine propositions - that is, do they make assertions that are susceptible of truth or false-hood and that could therefore provide the objects of genuine beliefs? ${ }^{138}$

Nonpropositional theories assert, in some way, that moral evaluations do not affirm the truth or falsity of moral propositions, while propositional theories assert that moral evaluations do affirm the truth or falsity of moral propositions.

Hume's position, within his moral philosophy, has been interpreted as either nonpropositional or propositional, or seen as inconsistent (in that he, on the surface, seems to contradict himself). The contradiction that Hume gets accused of is that "the first section of Book III of the Treatise [is devoted] to establishing that 'moral distinctions (are) not deriv'd from reason,"'139 while "in Treatise III.iii.1 ("Of the origin of the natural virtues and vices"), Hume describes various ways in which we

136 Don Garrett, Cognition and Commitment in Hume's Philosophy (Oxford: Oxford University Press, 1997), 188.

137 Garrett's "nonpropositional" vs. "propositional" distinction sounds quite similar to the noncognitive vs. cognitive distinction more broadly in the realism vs. antirealism debate.

138 Garrett, Cognition and Commitment in Hume's Philosophy, 188.

139 Ibid, 187. 
'correct' our moral sentiments by reflection" 140 (which seems to imply that moral distinctions could be derived from reason). The role this plays in Garrett's chapter is that Hume sometimes appears to be taking a nonpropositional position towards moral distinctions, and sometimes Hume appears to be taking a propositional position towards moral distinctions (in the context of moral evaluation). Garrett concludes that Hume's theory is both nonpropositional and propositional, and that it is not contradictory for Hume to hold both these seemingly contradictory positions.

Garrett clarifies what Hume means "[...] when Hume denies that moral distinctions are derived from reason," in first saying that Hume "does not use the term 'reason' in a vague or merely honorific sense":

Rather, [Hume] uses it as a technical term in his cognitive psychology. It is, here as elsewhere throughout his writings, the term that specifically designates the faculty of making inferences. He is not, therefore, asking whether moral distinctions are warranted or justifiable; instead, he is asking whether their occurrence can be explained as a product of inference operating on representations of the objects of evaluation, or whether we must instead recognize the occurrence of some specifically moral noninferential element. ${ }^{141}$

Therefore, according to Garrett, Hume's understanding of reason “designates the faculty of making inferences." For Hume, reason is not just a vague rational faculty. This is important, because inference ties back to Hume's metaphysics (especially his scepticism and naturalism). Following this first clarification, Garrett makes a second clarification,

Hume's arguments are directed toward answering the general question of whether the origin of the capacity to make moral distinctions depends only on reason or on something else (such as distinctively moral impressions). He is not addressing the more particular question of whether or not someone who

140 Ibid, 190.

${ }^{141}$ Ibid, 193. 
already has this capacity, based partly on his or her noninferential endowments, could infer the correctness of a moral evaluation. ${ }^{142}$

The second clarification is aimed at showing that Hume is addressing whether the source, or origin, "of the capacity to make moral distinctions" relies solely on this inferential reasoning, or if the source could possibly rely on something else (i.e. what Garrett calls moral impressions; Hume also uses the term 'sentiment').

And, as Garrett also remarks in the above quote, Hume is not addressing whether someone who has inferential rational endowments (partly based on moral impressions/sentiments) could make a moral evaluation about the rightness or wrongness of a moral proposition, etc.. Hume is concerned with the origin of the moral evaluation, not whether rational animals can assess the rightness or wrongness (i.e. correctness) of a moral proposition (moral fact, act, etc.). What spurs the moral evaluation to be 'moral'? After Hume articulates what he thinks is the origin of moral evaluation, he can then go on to articulate a further, more developed understanding of moral evaluation (which includes reflection and inferential reasoning).

For Hume, the origin of moral distinction is moral impression/sentiment. As Garrett says, "Hume insists that to feel a moral sentiment is itself a moral evaluation and the making of a moral distinction (e.g., at THN 471)."143 But, the key as to why Hume is not contradicting himself, as some interpreters mistakenly think, lies in Hume's movement from moral sentiment to reason. Garrett explains this move as follows,

\footnotetext{
142 Ibid.

143 Ibid, 196.
} 
Once we have functioning abstract ideas of vice, virtue, and their various degrees and species, we can formulate propositional judgments or beliefs to the effect that a particular person is virtuous, or that a particular mental characteristic is especially vicious, or that an action ought to be done. [...] Although such judgments are propositional in character, they are nevertheless dependent on the existence of moral feelings [i.e. sentiments] in two ways. First, the most common way of making such a judgment involves, as a preliminary, imaginatively taking up a steady and general point of view, so as to have moral feelings as a result of the sympathetic reactions that are elicited. Second, and even more fundamentally, no person could have the necessary abstract moral ideas in the first place unless that person had previously had moral sentiments from which such abstract ideas could have developed. Moreover, it is moral feelings, not the moral judgments that result from them, that are directly and independently motivating. ${ }^{144}$

We first have moral sentiment before we can have moral judgments that are propositional in nature (and therefore based on inference-and rational). This is why Hume says, as Garrett quotes him, “moral distinctions (are) not deriv'd from reason."145 Moral distinctions are not derived from reason; they are derived from moral sentiment. But, this does not mean that moral distinctions cannot become propositional, based on inferential reasoning for Hume, once the initial moral sentiments are felt. In order to know something for Hume, we must experience it first, and preferably multiple times before we can form a more abstract idea of it. Once we have a more abstract, or general, idea of what we have experience of, we can then reflect on it making it propositional and rational. ${ }^{146}$ For Garrett, this means

144 Ibid, 197-198.

145 Hume, Treatise, III.i.1.

146 A potential problem could arise here, but I cannot go into great detail in explaining or answering the problem due to time and space constraints. The problem is this: it could be said that a proposition that only reports one's own sentiment (based on one's own experiences) is not a moral proposition, because it does not report what is right or wrong in an universally applicable way. A quick answer: the issue with this problem is that it ignores part of what Hume was trying to say. Our experience of sentiment is only part of the moral proposition story. It begins with sentiment, but after the sentiment we can then reflect on that sentiment in order to weigh whether it is right or wrong. 
that "Hume recognizes both nonpropositional moral evaluations (moral feelings) and propositional moral evaluations (moral judgments as distinct psychological events." ${ }^{147}$ Nonpropositional moral feelings (i.e. sentiments) do not conflict with propositional moral judgements, for Hume, because we must first have the moral feeling before we can have the moral judgement (they are interconnected rather than contradictory).

After echoing Garrett's words that Hume's scepticism and naturalism “are mutually supporting"; I would add that Hume's scepticism, naturalism, and moral philosophy are all mutually supporting and cohesive. Hume's moral philosophy is based in cognitive psychology, as Garrett says, which relates back to Hume's "science of man" (i.e. naturalism) and Hume's desire to understand what makes humans 'human'. Hume's naturalistic approach is that of, what we would call in more contemporary times, a natural scientist and psychologist. His goal was to look for the source of knowledge, and the source of morality. But, interestingly, Hume's sincerity towards naturalism (or, perhaps, more accurately, a kind of scientific method) makes him acknowledge the limits of human knowledge, and doubt occurs in the realms that surpass what is immediately knowable through experience. This makes doubt natural. But, this does not mean that the kind of doubt that Descartes was famous for, such as the Method of Doubt (Academic Scepticism), is natural. Natural doubt, for Hume, is the suspension of belief due to the limits of human cognitive abilities (or, as Garrett refers to it, cognitive psychology).

147 Garrett, Cognition and Commitment in Hume's Philosophy, 199. 
Natural doubt, or the suspension of belief, or Pyrrhonian Scepticism does not mean that we cannot live our lives-this would entail a much more radical form of scepticism. It means that we must accept appearances due to the limited nature of human cognition. We (humans) should suspend belief when it comes to matters that go beyond our limited cognitive abilities; but this does not mean that we cannot make judgements, have knowledge, or make moral evaluations based on appearances. It only means that in our search for the sources of such things as knowledge and morality, for example, we must keep in mind that we are limited to human abilities (and cannot know anything beyond human abilities). Hume's philosophy boils down to: naturalism as the method, knowledge and morality as the result, and scepticism as a side effect due to the limits of human cognitive ability. 


\section{Chapter}

\subsection{Introduction}

There are many different interpretations of Hume's philosophy. He has been interpreted as a realist, an anti-realist, and a sceptic in efforts to explain his metaphysics, and reconcile it with his naturalism and moral philosophy. ${ }^{148}$ Different approaches have also been used: from accepting that there are 'two Humes' to efforts to reconcile his philosophy as cohesive to accepting that his philosophy is not cohesive. ${ }^{149}$ Many aspects of Hume's philosophy are hotly debated still, 242 years after his death. It will be my effort in this paper to join the debate surrounding Hume's philosophy in an effort to better understand Hume's philosophy as a cohesive whole. In order to better understand Hume's philosophy as a cohesive whole, I will need to address his metaphysics, naturalism, and his moral philosophy.

I will begin by supporting an understanding of Hume as a sceptic through using his writings in A Treatise of Human Nature (2.2.) and An Enquiry concerning Human Understanding (2.3.) as support. After which, I will touch on Hume's position concerning moral facts (2.4.). I will then make some qualifications on Hume's moral philosophy (2.5.), which will help support Humean Scepticism as an alternative in the moral realism and moral anti-realism debate (2.6.). Finally, I will venture some thoughts on other potential implications Humean Scepticism, given that it is an

\footnotetext{
148 Hume has been interpreted as a realist, an anti-realist, and a sceptic with regard to his views on causation, the external world, the self, and moral facts.

149 Jani Hakkarainen discusses this briefly in his paper "Hume's Scepticism and Realism". Jani Hakkarainen, "Hume's Scepticism and Realism," British Journal for the History of Philosophy 20, no. 2 (2012): 283-309.
} 
alternative in the moral realism and moral anti-realism debate, may have for metaethics in general (2.7.).

\subsection{Humean Scepticism in A Treatise of Human Nature}

I will start off by considering Hume's position on scepticism with regard to the external world. There are many ways in which someone can be a sceptic; they do not have to be a global, or radical, sceptic. But, I think that the foundation for my interpretation of Hume's scepticism starts with his scepticism of the external world, and moves forward from there. Scepticism with regard to the external world is the foundation for my interpretation of Hume's scepticism for one main reason: it provides a helpful framework for thinking about scepticism as an alternative in the realism and anti-realism debate.

In Hume's infamous Book I "Of the Understanding" in A Treatise of Human

Nature, he says in Part 4 "Of the sceptical and other systems of philosophy", Section 2 "Of scepticism with regard to the senses";

[T] he sceptic still continues to reason and believe, even tho' he asserts, that he cannot defend his reason by reason; and by the same rule he must assent to the principle concerning the existence of body, tho' he cannot pretend by any arguments of philosophy to maintain its veracity. Nature has not left this to his choice, and has doubtless esteem'd it an affair of too great importance to be trusted to our uncertain reasonings and speculations..$^{150}$

Hume is addressing scepticism with regard to the external world in this quote. In my reading of the above quote, I understand what is being articulated to be a form of Moderate Pyrrhonian Scepticism. ${ }^{151}$ While Hume does say that the sceptic "must

150 David Hume, A Treatise of Human Nature, eds. David Fate Norton and Mary J. Norton (Oxford: Oxford University Press, 2009), 1.4.2.1 (p. 125).

${ }^{151}$ I say "Moderate Pyrrhonian Scepticism" here, though this would just fall under what Sextus Empiricus calls "Pyrrhonian Scepticism". I use the word "Moderate" 
assent to the principle concerning the existence of body," he qualifies this statement when he says, "tho' [the sceptic] cannot pretend by any arguments of philosophy to maintain its veracity." The sceptic cannot help but give in to the appearance of body, "Nature has not left this to [the sceptic's] choice," but that does not mean that the sceptic can give an argument for the existence of body (or the Real ${ }^{152}$ world). ${ }^{153} \mathrm{~A}$ Moderate Pyrrhonian Sceptic can give in to appearances, so long as they acknowledge that they are just appearances and remain agnostic with regard to any argument for or against these appearances-since, according to Hume, our "reasonings and speculations" concerning this subject are uncertain.

deliberately in order to distinguish the scepticism I am referring to from the more radical Pyrrhonian Scepticism of Pyrrho himself. Pyrrho, according to anecdote, did not give into appearances, which resulted in his followers having to look after him so that he didn't die. This is not the Pyrrhonian Scepticism I am referring to. I am referring to the agnostic, suspension of judgement (epochē) kind of scepticism started by Pyrrho, but a more moderate form that acknowledges that one must give in to appearances to live their life.

152 When I use the word Real with a capital "R", I mean mind-independently real in the ontological sense (i.e. that something exists in the external world, and is not constructed by mental states or is not mind-dependent).

153 According to Hume, the sceptic cannot give a philosophical argument for their "assent to the principle concerning the existence of body," though this does not explicitly mean that the sceptic must give in to the appearance of the external world. It means that what we naturally give in to is the idea, or principle, of the external world (i.e. "the existence of body"), this idea, or principle, is something that we cannot help but believing - even though we cannot provide any philosophical, or rational, argument for our believing in the external world. It ends up being the case that the sceptic gives in to appearances, because when they reflect, or philosophize, they become aware that they cannot give an argument for why they think that the external world exists. Once they have this realization, they acknowledge that what they can know is only that they have ideas, or perceptions, of the external world, and what they can do, while they cannot give an argument as for why, is assent (or give in to) these ideas or perceptions (otherwise can be called appearances). 
In support of my understanding of what Hume says in the previous quote, we can go back to Book I, Part 2, Section 6 of A Treatise of Human Nature (the Treatise from here on),

A like reasoning will account for the idea of external existence. We may observe, that 'tis universally allow'd by philosophers, and is besides pretty obvious of itself, that nothing is ever really present with the mind but its perceptions or impressions and ideas, and that external objects become known to us only by those perceptions they occasion. To hate, to love, to think, to feel, to see; all is nothing but to perceive.

Now since nothing is ever present to the mind but perceptions, and since all ideas are deriv'd from something antecedently present to the mind; it follows, that 'tis impossible for us so much as to conceive or form an idea of any thing specifically different from ideas and impressions. Let us fix our attention out of ourselves as much as possible: Let us chace our imagination to the heavens, or to the utmost limits of the universe; we never really advance a step beyond ourselves, nor can conceive any kind of existence, but those perceptions, which have appear'd in that narrow compass. ${ }^{154}$

"Perception" can be replaced, in some instances, by what I have been calling "appearance" to better understand the connection between the above quote and my description of the previous quote. ${ }^{155}$ Hume states that all we have access to ("present with the mind") are our perceptions, impressions, and/or ideas-I will put these all under the umbrella of the word "appearances", and use "appearances" and "perceptions" interchangeably. ${ }^{156,157}$ Therefore, if all we have access to are our perceptions (appearances), then everything we experience is nothing but perception

154 David Hume, A Treatise of Human Nature, eds. David Fate Norton and Mary J. Norton (Oxford: Oxford University Press, 2009), 1.2.6.7-8 (p. 49).

155 The term "perception" is an umbrella term for Hume that includes a wide range of mental phenomena. The term "appearance" is often more strictly used to just represent physical objects (for example, to represent information gained via the senses, sensory impressions).

156 Mental ideas and impressions are perceptions for Hume; just as anything perceived via the senses are perceptions.

157 "Appearances" are often associated with sense impressions (perceptions gained via the senses), though "appearances" can be used more broadly to have the same meaning as Hume's understanding of "perceptions" (and are used more broadly in the context of Ancient or Pyrrhonian Scepticism). 
(whether our perceptions be of the Real/external world or of our own emotions/ affects/thoughts/ideas).

Interestingly, part of the above quote,

Now since nothing is ever present to the mind but perceptions, and since all ideas are deriv'd from something antecedently present to the mind; it follows, that 'tis impossible for us so much as to conceive or form an idea of any thing specifically different from ideas and impressions, ${ }^{158}$

expresses a direct attack on realism. Hume's conclusion from only perceptions being "present to the mind", and something comes from something before it, is that we cannot even think of anything external, or different, from the mind (perceptions, or appearances). We can only think of perceptions, because we only have access to perceptions. This is an attack on realism, because there is no way for us to have access to anything mind-independent. For example, the chair that I perceive myself to be sitting in is, and can only be, known to me through my perceptions of it. There is no way for me to have knowledge of the chair outside of my own perceptions. Realism requires some statement about mind-independence or objectivity, but, according to Hume, there is no way for us to know anything beyond the mind and that is always biased since the mind consists of our own perceptions.

Hume makes the claim that perceptions are caused by other perceptions (in a kind of antecedent-consequent relationship), and, therefore, we cannot even think of anything other than perceptions ("ideas and impressions"). He tries to emphasize his point by imploring us to think about the heavens or the farthest reaches of the universe-our thoughts of these things are just that, thoughts (or perceptions). This

${ }^{158}$ Hume, A Treatise of Human Nature, 1.2.6.8 (p. 49). 
is because "we never really advance a step beyond ourselves, nor can conceive any kind of existence, but those perceptions, which have appear'd in that narrow compass." ${ }^{159}$ We are stuck within the realm of our perceptions (or the realm of appearances). Due to this, we cannot help but give into these perceptions/ appearances in order to live our lives. But, that does not mean, as Hume says at 1.4.2.1., that we can give any reasoning for those perceptions (concerning the existence of the external world)—at least not "by any arguments of philosophy", by which I take Hume to mean external arguments (or metaphysical/ontological arguments). ${ }^{160}$ We cannot give these kinds of arguments for our perceptions, because we do not have access to them (since the proof/justification for them seems to be beyond our perceptions).

\section{At 1.4.2.4., Hume says,}

That our senses offer not their impressions as the images of something distinct, or independent, and external, is evident; because they convey to us nothing but a single perception, and never give us the least intimation of any thing beyond. A single perception can never produce the idea of a double existence, but by some inference either of reason or imagination. When the mind looks further than what immediately appears to it, its conclusions can never be put to the account of the senses; and it certainly looks further, when from a single perception it infers a double existence $[\ldots] .161$

By "double existence", Hume is addressing the distinction between the perception itself and the external object that the perception was, apparently, perceived from.

159 David Hume, A Treatise of Human Nature, eds. David Fate Norton and Mary J. Norton (Oxford: Oxford University Press, 2009), 1.2.6.8 (p. 49). 160 See Rudolf Carnap's paper/chapter "Empiricism, Semantics, and Ontology" for a detailed distinction between internal and external questions. Rudolf Carnap, "Empiricism, Semantics, and Ontology," in Meaning and Necessity: A Study in Semantics and Modal Logic, Second Edition (Chicago: The University of Chicago Press, 1956).

${ }^{161}$ Hume, $A$ Treatise of Human Nature, 1.4.2.4 (p. 126). 
The problem being that our sense impressions (perceptions gained via the senses) do not give us the existence of both the sense impression and the external objectsense impressions only give us sense impressions, we do not have access to the external object that we have come to believe in due to "reason or imagination". I interpret Hume to be referring to specifically-when he expresses that no philosophical arguments for the external world can be given—-metaphysical arguments that try to argue for something beyond our perceptions. And, this seems to be a further attack on realism, as well as an attack on anti-realism. It attacks both, because both are dogmatic in asserting something about the external world that Hume does not think we have access to (because their assertions are beyond our perceptions). The realist asserts that there is something beyond our perceptions and we can know it, and the anti-realist asserts that there is nothing beyond our perceptions and we can know that there is nothing beyond our perceptions.

It is also important to note that Hume addresses the impressions (i.e. perceptions) we gain from our senses specifically,

As to those impressions, which arise from the senses, their ultimate cause is, in my opinion, perfectly inexplicable by human reason, and 'twill always be impossible to decide with certainty, whether they arise immediately from the object, or are produc'd by the creative power of the mind, or are deriv'd from the author of our being. Nor is such a question any way material to our present purpose. We may draw inferences from the coherence of our perceptions, whether they be true or false; whether they represent nature justly, or be mere illusions of the senses. ${ }^{162}$

It is clear that Hume is taking an agnostic (sceptical) stance when it comes to what is the "ultimate cause" of the impressions (i.e. perceptions) we gain from the senses in saying that the "ultimate cause" is "inexplicable by human reason"—-there is no

162 Ibid, 1.3.5.2 (p. 59). 
philosophical (metaphysical) reason we can give to justify the ultimate cause of our perceptions (that we gain via the senses) being directly from the external object itself, created by our mind, or created by "the author of our being" (for example, God). Hume then takes his position a step further by saying that the ultimate cause of our perceptions is not important to our present purposes, because we can "draw inferences from the coherence of our perceptions." And, that it does not actually matter whether our perceptions are true or false, ${ }^{163}$ represent the Real world correctly, or are mere figments of our imagination (mental thoughts/ideas). The import-ant point is that we can assent to these perceptions (or appearances) via the inferences we make "from the coherence of our perceptions".

Hume seems to being saying that we can make inferences via the "coherence of our perceptions", and not bother ourselves with the ultimate cause of our perceptions. For Hume, it does not matter what the ultimate cause of our perceptions is, because we have no way of knowing what the ultimate cause is. But, this does not mean that we cannot make inferences via the coherence, or regularity, of our perceptions-though these inferences will never give you $100 \%$ certainty.

In the Treatise, Hume makes a distinction between philosophy and the vulgar (or the philosopher and the vulgar/common person). Hume makes this distinction

163 True or false in the sense of corresponding to the Real, external world; as well as verifiably true or false with respect to this correspondence to the Real, external world (and we can know/have access to whether our perceptions are true or false with respect to this correspondence). This does not mean that through some other means, such as the coherence (or constant conjunction) of our perceptions, we cannot provide an alternative grounds for our perceptions in which we can assess whether they are true or false. Hume can be interpreted as saying exactly that: we can assess our perceptions to be true or false (or some perceptions to be more true than others) with reference to the coherence of some perceptions, for example. 
to show that the philosopher and the non-philosopher are both in a kind of trouble.

The philosopher tries to give arguments for beliefs (such as the belief of the Real existence of the external world) that they cannot give arguments for, while the vulgar, or common person, cannot give any arguments at all for their beliefs. Of the two positions, Hume says,

[W] hatever convincing arguments philosophers may fancy they can produce to establish belief of objects independent of the mind, 'tis obvious these arguments are known but to very few, and that 'tis not by them, that children, peasants, and the greatest part of mankind are induc'd to attribute objects to some impressions, and deny them to others. [...] For philosophy informs us, that every thing, which appears to the mind, is nothing but a perception, and is interrupted, and dependent on the mind; whereas the vulgar confound perceptions and objects, and attribute a distinct continu'd existence to the very things they feel or see. [...] [A]s long as we take our perceptions and objects to be the same, we can never infer the existence of the one from the other, nor form any argument from the relation of cause and effect; which is the only one that can assure us of matter of fact. Even after we distinguish our perceptions from our objects, 'twill appear presently, that we are still incapable of reasoning from the existence of one to that of the other: So that upon the whole our reason neither does, nor is it possible it ever shou'd, upon any supposition, give us an assurance of the continu'd and distinct existence of body. That opinion must be entirely owing to the IMAGINATION [...].164

Along with the distinction between philosophy and the vulgar, he makes some interesting claims in the above quote (all from the same paragraph). At an initial glance, the two positions, the philosophical and the vulgar, are not compatiblephilosophy produces arguments, while the vulgar naturally confound perceptions and objects to produce the belief of "a distinct continu'd existence" (of external objects/the external world) without much thought to the matter.

The vulgar position, the conflation of perceptions and objects, ${ }^{165}$ does not allow us, according to Hume, to differentiate between perceptions and objects, or

164 Ibid, 1.4.2.14 (p. 129).

165 Real, external objects. 
give us an argument for cause and effect. It does not allow us to infer cause and effect, because the vulgar view does not allow us to infer the antecedent and the consequent (which is what gives us cause and effect, according to Hume). ${ }^{166}$ Even if we could distinguish between perceptions and objects, our reasoning is limited, and cannot actually give us an adequate argument for "the continu'd and distinct existence of body" (or the Real, external world). ${ }^{167}$ The philosophical position, for Hume, is not on strong grounds either. As Hume says,

[W] hatever convincing arguments philosophers may fancy they can produce to establish belief of objects independent of the mind, 'tis obvious these arguments are known but to very few, and that 'tis not by them, that children, peasants, and the greatest part of mankind are induc'd to attribute objects to some impressions, and deny them to others. ${ }^{168}$

Whatever arguments philosophers can produce in order to prove external objects are known to very few; the vast majority of people take the vulgar position. Though, again, the vulgar cannot provide any arguments for or against their position (of the conflation of perceptions and objects). Both the philosopher and the vulgar person are in bad positions-both are not justified in giving arguments (even if the philosopher thinks they are), but at least the vulgar does not attempt to give an argument for their position.

Hume goes on to say,

Now we have already observ'd, that however philosophers may distinguish betwixt the objects and perceptions of the senses; which they suppose coexistent and resembling; yet this is a distinction, which is not comprehended by the generality of mankind, who as they perceive only one being, can never

166 Think back to 1.2.6.8 (p. 49).

167 Due do human reason being limited, whether you are educated as a philosopher or not, the philosophical position and the vulgar position both cannot give adequate arguments for "the continu'd and distinct existence of body". 168 Treatise, 1.4.2.14 (p. 129). 
assent to the opinion of a double existence and representation. Those very sensations, which enter by the eye or ear, are with them the true objects, nor can they readily conceive that this pen or paper, which is immediately perceiv'd, represents another, which is different from, but resembling it. In order, therefore, to accommodate myself to their notions, I shall first suppose, that there is only one single existence, which I shall call indifferently object or perception, according as it shall seem best to suit my purpose, understanding by both of them what any common man means by a hat, or shoe, or stone, or any other impression, convey'd to him by the senses. ${ }^{169}$

The vulgar (or "generality of mankind" or "common man"), can only consent to their impressions (or perceptions) of external objects. The vulgar cannot distinguish between an external object and their perception of that object, and cannot give an explanation as to the connection between said external object and their perception of it. This means that the vulgar person gives in to appearance. But, giving into appearances does not mean that one can give an explanation and so does not assert knowledge of the cause of the perception. This is still a form of Moderate Pyrrhonian Scepticism that Hume is articulating here for the vulgar position-it is just that the vulgar person does not realise that they are giving into appearances to live their lives. ${ }^{170}$

Returning back to the philosophical position, Hume writes, There are no principles either of the understanding or fancy, which lead us directly to embrace this opinion of the double existence of perceptions and objects, nor can we arrive at it but by passing thro' the common hypothesis of the identity and continuance of our interrupted perceptions. Were we not first persuaded, that our perceptions are our only objects, and continue to exist even when they no longer make their appearance to the senses, we shou'd never be

169 Ibid, 1.4.2.31 (p. 134).

170 The vulgar person gives in to appearance without argumentation or explanation, which is what the Moderate Pyrrhonian Sceptic does. The only difference between the vulgar person and the Moderate Pyrrhonian Sceptic is that the Moderate Pyrrhonian Sceptic realizes that they give in to appearance, because they have reflected and acknowledge that they cannot give an argument for their belief in the appearance of the external world. It is an appearance of an external world, because they only can know their perceptions (and perceptions are appearances). 
led to think, that our perceptions and objects are different, and that our objects alone preserve a continu'd existence. 171

The philosophical position is actually in a worse situation than the vulgar position, because it starts from the vulgar position and then tries to give an argument for the separate existence of perceptions and objects. The philosophical position starts off from the vulgar position, because everyone starts from the same position: unable to distinguish between external objects and their perceptions of them. But, the vulgar position stops there, it does not try to give an argument for the existence of external objects. Where the philosophical position goes wrong is in trying to give arguments for the existence of external objects-and Hume does not think that such arguments can rationally be given. The vulgar may not be able to give an argument for their position, but this is actually better, at least to Hume, because in not giving principles (or proof) they also do not make up something that is not founded on proper reason (as Hume accuses philosophers of doing).

It actually appears as though Hume is arguing against realism in his argument against the philosophical position. Directly after the above quote, Hume continues his argument against the philosophical position,

As to the first part of the proposition, that this philosophical hypothesis has no primary recommendation, either to reason or to the imagination, we may soon satisfy ourselves with regard to reason by the following reflections. The only existences, of which we are certain, are perceptions, which being immediately present to us by consciousness, command our strongest assent, and are the first foundation of all our conclusions. The only conclusion we can draw from the existence of one thing to that of another, is by means of the relation of cause and effect, which shows, that there is a connexion betwixt them, and that the existence of one is dependent on that of the other. The idea of this relation is deriv'd from past experience, by which we find, that two beings are constantly conjoin'd together, and are always present at once to the mind. But as no beings are ever present to the mind but perceptions; it follows that we may observe a

171 Ibid, 1.4.2.46 (p. 140). 
conjunction or a relation of cause and effect betwixt different perceptions, but can never observe it betwixt perceptions and objects. ${ }^{172}$

At this point, Hume moves away from explicitly talking about the scepticism with regard to the external world, and moves more towards scepticism with regard to causation. It is implicitly about scepticism with regard to the external world, because it is not that Hume doubts that there is causation; he doubts that we can know causation other than from the 'constant conjunction' of cause and effect. Hume re-emphasizes that we can only be certain of the existence of perceptions. This is knowledge on an internal level, and states nothing ontological about the external world. We can infer from cause and effect the existence of one thing to another, but since this is based on past experience (of constant conjunction), and all past experience is based on perception, all this gives us is the existence of one perception to the existence of another perception-not the existence of a perception to the existence of an external object. For Hume, you cannot jump from experiencing the perceptions of seeing a pen fall off a desk onto the ground to stating that the pen Really exists just because you experienced perceptions of it. Through seeing the pen fall off the desk multiple times (the effect), perhaps you can infer that there is a force acting upon the pen (the cause)—but you cannot give an argument or an account as to what is beyond your perceptions in the external world (the ultimate, Real origin of the cause). So, while you can infer, based on your perceptions, a cause and an effect, that cause and that effect are still only within your perceptions.

This seems to be an argument against the realist position, because it argues that we are not founded, by reason, to assert the existence of external objects-and

172 Ibid, 1.4.2.47 (pp. 140-141). 
most realists require cognitivism (that a claim can be true or false, and some claims can be verified as true), which generally requires being able to verify the truth or falsity of something against the Real world. If we never have access to the Real, external world and all we have access to are our perceptions, this seems to state that, in the very least, realism is not based on reason for Hume. If realism is not based on reason, then it is an irrational position to hold. In the very least, the burden of proof is on the realist to prove a Real, external world, and how we (humans) have access to it (i.e. can acquire knowledge beyond our perceptions).

It would seem that since all we have are our perceptions, we must rely on inference (not certainty), and that we cannot help but live our lives by way of appearances that Hume's position is an agnostic position when it comes to the Real world. ${ }^{173}$ It is agnostic in the sense of Moderate Pyrrhonian Scepticism, and is a form of scepticism in relation to metaphysics-more specifically ontology. Hume does not think that we can assert anything about the Real world (i.e. external objects). This lack of ability to rationally construct an argument for the Real world under-mines any dogmatic position ${ }^{174}$ towards the Real world. It does so, because the realist cannot rationally argue for external objects out of only perceptions and the anti-realist cannot assert anything along the lines that our perceptions do not match the Real world (because they cannot know that either from only perceptions).

${ }^{173}$ Hume's position is agnostic, or sceptical, because asserting that we can have knowledge beyond our perceptions is not rational for Hume. We have limited knowledge based on experience gained through perceptions (which do not give us direct access to the external world beyond our perceptions). The agnostic, or sceptical, position does not prove or disprove realism or anti-realism. But, it does try to show that asserting anything dogmatic (via realism or anti-realism) is not based on anything we have access to, and is not rational. ${ }^{174}$ Dogmatic positions referring to a realist or anti-realist position. 
The only rational position is the sceptical position, because it does not try to overstep its bounds.

He further supports that his understanding of the Real, external world is understood through a sceptical lens towards the end of Book I, Part 4, Section 2;

I begun this subject with premising, that we ought to have an implicit faith in our senses, and that this wou'd be the conclusion, I shou'd draw from the whole of my reasoning. But to be ingenuous, I feel myself at present of a quite contrary sentiment, and am more inclin'd to repose no faith at all in my senses, or rather imagination, than to place in it such an implicit confidence. I cannot conceive how such trivial qualities of the fancy, conducted by such false suppositions, can ever lead to any solid and rational system. They are the coherence and constancy of our perceptions, which produce the opinion of their continu'd existence; tho' these qualities of perceptions have no perceivable connexion with such an existence. ${ }^{175}$

Hume states that he has no faith in his senses, and I take this to mean that he has no faith that his senses give him knowledge of the external world. His senses give him perceptions, and perceptions may be accurate or not-we cannot know, at least not ontologically (with reference to the external world). Any philosophical theory or system based on false attributions to the external world is not metaphysically founded and not rational. It is the regularity of our perceptions that give us our understanding of the continued existence of external objects, though we have no way via our perceptions to prove the continued existence of external objects.

Though, Hume does indicate that people will oscillate between different positions on the Real, external world, but says, "Carelessness and in-attention alone can afford us any remedy."176 I take this to mean that the vulgar, or common, position is the only easy answer to ontological problems. The vulgar position allows us to assent to

175 Ibid, 1.4.2. 56 (pp. 143-144).

176 Ibid, 1.4.2.57 (p. 144). 
appearances without argument, and live our lives. Even though, the vulgar position is not any more rational than the philosophical position, except that the vulgar position does not attempt to give philosophical, or metaphysical, arguments for the external world (which redeems the vulgar position in that the vulgar position does not try to argue for things beyond any human's cognitive ability or any human's access to knowledge via perceptions).

\subsection{Humean Scepticism in An Enquiry concerning Human Understanding}

At the beginning of Section XII "Of the Academic or Sceptical Philosophy", Hume addresses Academic Scepticism, and Descartes' Method of Doubt. Hume does not think that Academic Scepticism, or radical doubt, is feasible, because he does not think that it is possible via a chain of reasoning to deduce any first or foundational principle that is not "fallacious or deceitful" (since all the other principles appear to be "fallacious or deceitful"). ${ }^{177}$ If you are going to doubt almost all your principles, why would you not also doubt your foundational principle(s)? If you can doubt most things, where does the doubt stop? As Hume says,

The Cartesian doubt, therefore, were it ever possible to be attained by any human creature (as it plainly is not) would be entirely incurable; and no reasoning could ever bring us to a state of assurance and conviction upon any subject. ${ }^{178}$

This kind of radical doubt is "incurable", and there would be no way to know anything—not even internally. ${ }^{179}$ But, we need to be careful when considering this criticism of Academic Scepticism, or radical doubt, because this criticism does not

177 David Hume, An Enquiry concerning Human Understanding, ed. Peter Millican (Oxford: Oxford University Press, 2008), 12.3 (p. 109).

178 Ibid.

179 "Internally" here is meant to be understood in the Carnapian sense of "internal". 
mean that Hume is criticizing all forms of scepticism. Hume can still be open to the idea of Pyrrhonian Scepticism, though, as we'll see, he endorses Moderate Pyrrhonian Scepticism. Hume shows apprehension towards any kind of radical philosophy throughout the whole of An Enquiry concerning Human Understanding (referred to as the First Enquiry from here on).

Hume writes that, according to the common or vulgar position, people are bound to assume that the external world "would exist, though we and every sensible creature were absent or annihilated;"180 and

philosophy, [...] teaches us, that nothing can ever be present to the mind but an image or perception, and that the senses are only the inlets, through which these images are conveyed, without being able to produce any immediate intercourse between the mind and the object.181

Philosophy appears at conflict with the common opinion at this point in the First Enquiry, because it goes beyond being bound to think something and attempts to give an explanation for something that it cannot actually explain. But, then, Hume goes on to say,

But [...] philosophy finds herself extremely embarrassed, when she would justify this new system, and obviate the cavils and objections of the sceptics. She can no longer plead infallible and irresistible instinct of nature: For that led us to a quite different system, which is acknowledged fallible and even erroneous. And to justify this pretended philosophical system, by chain of clear convincing argument, or even any appearance of argument, exceeds the power of all human capacity. ${ }^{182}$

The problem for philosophy arises when it tries to justify itself by "chain of clear convincing argument", because this is beyond the human capacity for reason (we cannot get outside of ourselves, or trace back to any foundational principle, to see if

180 Ibid, 12.7 (p. 110).

181 Ibid, 12.9 (p. 111).

182 Ibid, 12.10 (p. 111). 
our chain of reasoning is correct). ${ }^{183}$ This is why the philosopher must endorse the sceptical position, or fall back into the common, or vulgar, position. The philosopher must endorse scepticism or fall back into the vulgar position due to a lack of grounding ${ }^{184}$ for any dogmatic position. The sceptical position, meaning the agnostic posit-ion recognizes that we cannot give a metaphysical argument for the external world/basis of our perceptions, while the vulgar position does not even try to give a metaphysical argument.

The philosophical position, when a sceptical philosophical position, is not in conflict with the common/vulgar opinion, because neither attempt to give a metaphysical argument for the existence of the external world. Hume's sceptical approach is articulated in Section XII, Part I, Paragraph 12 of his First Enquiry,

It is a question of fact, whether the perceptions of the senses be produced by external objects, resembling: How shall this question be determined? By experience surely; as all other questions of a like nature. But here experience is, and must be entirely silent. The mind has never any thing present to it but the perceptions, and cannot possibly reach any experience of their connexion with objects. The supposition of such a connexion is, therefore, without foundation in reasoning. 185

While we perceive the 'external' world via our senses, we never perceive the connection between our perceptions and the external world. And, so, no account, not even through experience, can give us an argument or foundation, because all we

183 This both supports the criticism found in the Treatise that we cannot get beyond our perceptions, but it also is a criticism against Academic Scepticism in the form of Cartesian Scepticism/Doubt. It ends up being a criticism of Cartesian Scepticism/ Doubt, because Cartesian Scepticism/Doubt ends up being dogmatic in that it tries to assert a foundational principle that we some how know with certainty. Hume does not like any dogmatic philosophy that oversteps its bounds, and tries to assert things that are beyond what human beings can know via solely perceptions.

${ }^{184}$ By grounding, I mean philosophical, or metaphysical, argument. 185 Ibid, 12.12 (p. 112). 
perceive are our perceptions-and not the connection between our perceptions and the external world. No matter how many times we perceive a book that we own or the pen that we like to use, we never perceive the connection between our perception of that book or pen, and the Real book or pen. All we have access to is our perception(s) of that book or pen. Experience can help us make inferences, like that of cause and effect, but it cannot give us an explanation for any connection between perception and the Real world. This assertion that we cannot give an explanation or argument or proof of any sort does not mean that the connection may not be there. It means that we must not make an argument for something that is outside of our [human] reasoning. Therefore, Paragraph 12 asserts an agnostic, or Pyrrhonian, form of scepticism. ${ }^{186}$

Hume, interestingly, gives what looks like a serious challenge, on the face of it, to Pyrrhonian Scepticism in Section XII of the First Enquiry-which could be one of the reasons why some people do not interpret Hume as a sceptic. He says,

The great subverter of Pyrrhonism or the excessive principles of scepticism, is action, and employment, and the occupations of common life. [Sceptic] principles may flourish and triumph in the schools; where it is, indeed, difficult, if not impossible, to refute them. But as soon as they leave the shade, and by the presence of the real objects, which actuate our passions and sentiments, are put in opposition to the more powerful principles of our nature, they vanish like smoke, and leave the most determined sceptic in the same condition as other mortals. ${ }^{187}$

186 Paragraph 12 does not assert an anti-realist position, because the anti-realist position still tries to assert something too much about the external world-for example, that we know that our perceptions are not produced by the external world. For Hume, reason does not support any claim, positive or negative, about the Real existence of the external world., and, therefore, we cannot say anything about it or give any metaphysical argument for such dogmatic claims. 187 Ibid, 12.21 (pp. 115-116). 
I think it is important to clarify that Hume is referring to excessive, or radical, Pyrrhonism, more along the lines of what Pyrrho himself was reported to practice. Common life takes over even for those who endorse radical Pyrrhonian Scepticism, whether they like it or not. They have to assent to some perceptions, for example, or they die. ${ }^{188}$ And, so, Hume's challenge to radical Pyrrhonism makes a good point that is difficult to refute.

Though, this does not mean that Hume is not still a sceptic. As I said before, Hume does not seem to have liked any kind of radical opinion; this includes radical sceptical opinion. Hume highlights that radical Pyrrhonism is not viable, while also highlighting that common people still cannot justify their beliefs:

When [the radical Pyrrhonian Sceptic] awakes from his dream, he will be the first to join in the laugh against himself, and to confess, that all his objections are mere amusement, and can have no other tendency than to show the whimsical condition of mankind, who must act and reason and believe; though they are not able, by their most diligent enquiry, to satisfy themselves concerning the foundation of these operations, or to remove the objections, which may be raised against them. 189

Mankind, or both common people and philosophers, cannot justify "the foundation of [their] operations," and so end up in a moderate sceptical position: they cannot justify the Real world, they must just assent to appearances (i.e. perceptions) and live their lives.

This "mitigated scepticism," according to Hume, can "be both durable and useful."190 It is useful because it shows that

188 Like eating and drinking due to hunger and thirst, or the common belief that you are alive since you are perceiving and experiencing (such as you are hungry or thirsty and need these things to continue being alive).

${ }^{189}$ Ibid, 12.23 (p.117). ${ }^{190}$ Ibid, 12.24 (p. 117). 
[t]he illiterate may reflect on the disposition of the learned, who, amidst all the advantages of study and reflection, are commonly still different in their determinations: And if any of the learned be inclined, from their natural temper, to haughtiness and obstinacy, a small tincture of PYRRHONISM might abate their pride, by shewing them, that the few advantages, which they may have attained over their fellows, are but inconsiderable, if compared with the universal perplexity and confusion, which is inherent in human nature. In general, there is a degree of doubt, and caution, and modesty, which, in all kinds of scrutiny and decision, ought for ever to accompany a just reasoner. ${ }^{191}$

This harkens back to the philosopher and the common people. Though, the philosopher is educated, this does not mean that they are in a position that is any better than the common person. "[A] small tincture of PYRRHONISM" can show the educated that they are not any better off than the uneducated. None of us can explain or give an argument for the connection between our perceptions and the external world-we cannot step outside of our perceptions to receive some special knowledge. We are all on the same playing field. While the common person automatically does not attempt to give an explanation of how our perceptions correlate to the external world (or not), the educated person (the philosopher) requires Moderate Pyrrhonian Scepticism in order to understand that they cannot give an explanation of how our perceptions correlate to the external world (or not).

Towards the end of Section XII, Hume writes,

The existence, therefore, of any being can only be proved by arguments from its cause or its effect; and these arguments are founded entirely on experience. If we reason à priori, any thing may appear able to produce anything. The falling of a pebble may, for ought we know, extinguish the sun; or the wish of a man controul the planets in their orbits. It is only experience, which teaches us the nature and bounds of cause and effect, and enables us to infer the existence of one object from that of another. 192

191 Ibid, 12.24 (pp. 117-118).

192 Ibid, 12.29 (pp.119-120). 
This is again about cause and effect, and again has its roots in Hume's scepticism about the external world. How we gain knowledge of cause and effect is purely through experience, and not through having direct access to the external world. Experience is gained through perception, and therefore any existence we perceive is based on perception. We cannot reason a priori about the existence of external objects, like Descartes would have us attempt, because that will lead us down a worse road. We cannot rely on any ultimate cause or first principle(s), because we have no way of accessing/knowing them.

\subsection{Hume's Moral Philosophy}

The purpose of morality, for Hume, is social in constitution. Moral facts (or claims or propositions) are a set of rules (or laws) to live by within a given society. The ontological status of moral facts (or claims or propositions) is similar to the status of natural facts within Hume's philosophy. Arguably, Hume espouses a type of consequentialism, more specifically a type of indirect consequentialism, in his $A n$ Enquiry concerning the Principles of Morals (I will also refer to it as the Second Enquiry). ${ }^{193}$ And, so, to begin with, I will give brief definitions of consequentialism and indirect consequentialism before outlining my interpretation of Hume's moral philosophy.

Walter Sinnott-Armstrong in the Stanford Encyclopedia of Philosophy article titled "Consequentialism", defines consequentialism as follows,

${ }^{193}$ I start my sentence off with "arguably", because there is no consensus on whether Hume was any kind of consequentialist. I am reading Hume as a consequentialist, because it helps further my purpose of using my specific interpretation of Hume to give an alternative option in the moral realism and moral anti-realism debate. 
Consequentialism, as its name suggests, is the view that normative properties depend only on consequences. This general approach can be applied at different levels to different normative properties of different kinds of things, but the most prominent example is consequentialism about the moral rightness of acts, which holds that whether an act is morally right depends only on the consequences of that act or of something related to that act, such as the motive behind the act or a general rule requiring acts of the same kind. ${ }^{194}$

The emphasis in consequentialism is on the consequences of an action, and like in most forms of consequentialism, the act itself has only instrumental value, whereas desirable consequences have intrinsic value (the value that ultimately justifies the act with such consequences). This puts an emphasis on utility (insofar as acts are concerned), because if an act is not useful in bringing about a certain end-then it has no value within a consequentialist framework. Under the broader heading of consequentialism, there are a number of different forms. One of these forms of consequentialism is something called indirect consequentialism, and SinnottArmstrong says that

an indirect consequentialist holds that the moral qualities of something depend on the consequences of something else. [...] The most common indirect consequentialism is rule consequentialism, which makes the moral rightness of an act depend on the consequences of a rule. 195

Therefore, under indirect consequentialism, the consequences are not just dependent on the act, but on something else outside of the act (that influences the consequences of the act). As the above quote says, rule consequentialism is the most common form of indirect consequentialism. Rule consequentialism tries to assess the different consequences of different sets of rules (in terms of the impact(s) of

194 Walter Sinnott-Armstrong, "Consequentialism", The Stanford Encyclopedia of Philosophy, ed. Edward N. Zalta (Winter 2015 Edition), accessed on May 29th 2018 , https://plato.stanford.edu/archives/win2015/entries/consequentialism/. 195 Ibid. 
possible systems of rules), and the consequences of an act are, therefore, dependent on a set of rules (or laws). This set of rules is chosen by the society it governs, and is what makes the act (and the consequences that follow) morally right or wrong. The goal of consequentialism, in general, is to produce optimal consequences. Often this gets translated, as it does in utilitarianism, as an act (whether governed by rules or not) needs to produce the most happiness or pleasure for the society. The most happiness, or pleasure, is the most desirable consequence. ${ }^{196}$

I do think that Hume expresses a kind of indirect consequentialism in the Second Enquiry. ${ }^{197}$ Preparing us, the readers, at the end of the First Enquiry for the Second Enquiry, Hume says,

It is only experience, which teaches us the nature and bounds of cause and effect, and enables us to infer the existence of one object from that of another. Such is the foundation of moral reasoning, which forms the greater part of human knowledge, and is the source of all human action and behaviour. 198

I think it is important to note here that I think that Hume's consequentialism is dependent on his understanding of metaphysics (which his understanding of perceptions and their role in our understanding in how we know the external world

${ }^{196}$ For example, it could be argued that, for Hume, the overall happiness, or pleasure, of a given society is the most desirable consequence. In addition, it could further be argued that Hume either means this to be applied to a particular society (each society could have the same goal of happiness, but the formulation could be slightly different in each separate society) or to the whole of the human species (or future humanity).

197 Though, consequentialism is a, potentially, problematic term to refer to Hume's normative moral philosophy as, because it is a term that came after Hume was alive. 198 First Enquiry, 12.29 (p. 120). 
is also based on). Experience is the foundation of moral reasoning, and therefore moral reasoning is in the realm of matters of fact (not relations of ideas). ${ }^{199}$

In contemporary moral philosophy, we tend to separate normative moral theories from metaphysics (or metaethics), but I do not think that is so easily done in Hume's philosophy. ${ }^{200}$ Hume's project in the Treatise, as well as in the First Enquiry and Second Enquiry, is to give a comprehensive understanding of philosophy (especially the philosophical issues that were prominent during his time). To do this, he begins with metaphysics (i.e. the external world, and how we come to associate our perceptions with external objects), and uses this as a basis to build both his naturalism and moral philosophy on.

It will be my goal in this section to give an articulation of Hume's moral philosophy. My ultimate goal in this paper is to show that Hume is consistent through his understanding of metaphysics (i.e. that he is a Moderate Pyrrhonian Sceptic when it comes to metaphysics), and his understanding of moral philosophy in order to give an alternative position in the moral realism and moral anti-realism debate. His moral philosophy cannot be understood without understanding his metaphysical position that underpins them both. Therefore, Hume's moral philosophy cannot only be understood through a normative lens, but must also be understood through a metaethical ${ }^{201}$ lens as well (since its underpinnings are more

\footnotetext{
${ }^{199}$ I say not in the realm of relations of ideas, because relations of ideas are $a$ priori for Hume. Matters of fact are based in experience, and experience "is the foundation of moral reasoning."

$200 \mathrm{Or}$, in anyone's philosophy who is trying to give a comprehensive and whole analysis of most of the major areas within philosophy.

${ }^{201}$ Definition of metaethics: "The second-order activity of investigating the concepts of methods of ethics, rather than directly engaging with practical ('first-order')
} 
abstract). Morality, for Hume, is definitely within the practical domain, but its foundation in metaphysics is theoretical.

In Section 1 "Of the General Principles of Morals" of the Second Enquiry, Hume lays out the metaethical debate that he is situating himself within as follows,

There has been a controversy started of late, much better worth examination, concerning the general foundation of MORALS; whether they be derived from REASON, or from SENTIMENT; whether we attain the knowledge of them by a chain of argument and induction, or by an immediate feeling and finer internal sense; whether, like all sound judgment of truth and falsehood, they should be the same to every rational intelligent being; or whether, like the perception of beauty and deformity, they be founded entirely on the particular fabric and constitution of the human species. ${ }^{202}$

The debate that Hume is laying out is a metaethical debate: how morals are formed, or what the source of morality is. He positions himself within the metaethical debate before going on to articulate his normative moral theory based on his position within the metaethical debate.

Moral philosophy has one aim, and two main aspects for Hume. Its aim "is to teach us our duty; and, by proper representations of the deformity of vice and beauty of virtue, beget corresponding habits, and engage us to avoid the one and embrace the other." 203 This aim is achieved by the understanding, and by the affections (or emotions/passions). In support of this Hume says,

[Inferences and conclusions of the understanding] discover truths: But where the truths which they discover are indifferent, and beget no desire or aversion.

issues of what to do and how to behave. The distinction is apt to blur, in that different views about the structure of ethics usually have implications for the firstorder decision making."

Simon Blackburn, "metaethics," in the Oxford Dictionary of Philosophy, Third Edition (Oxford: Oxford University Press, 2016), 302.

202 David Hume, An Enquiry concerning the Principles of Morals, ed. Tom L. Beauchamp (Oxford: Oxford University Press, 2009), 1.3 (pp. 73-74). ${ }^{203}$ Ibid, 1.7 (p. 75). 
They can have no influence on conduct and behaviour. What is honourable, what is fair, what is becoming, what is noble, what is generous, takes possession of the heart, and animates us to embrace and maintain it. What is intelligent, what is evident, what is probable, what is true, procures only cool assent of the understanding; and gratifying a speculative curiosity, puts an end to our researches. ${ }^{204}$

After saying this, Hume goes so far as to say, in the Second Enquiry at 1.8, that to get rid of the affections, as they pertain to morality, would make morality "no longer a practical study, nor [have] any tendency to regulate our lives and actions."205 Then, at 1.9 of the Second Enquiry, Hume makes the strong claim that "reason and sentiment concur in almost all moral determinations and conclusions." 206 He goes on to explain in 1.9 how reason (the understanding) and sentiment (affections) both play a role in morality, and investigating this is the overarching focus of the Second Enquiry.

In his search for the roles that reason and sentiment play in morality, Hume says that there is one principle, a consequentialist principle, that morality is guided by, and that principle is utility. ${ }^{207}$ In regard to this principle of utility, Hume writes,

In all determinations of morality, this circumstance of public utility is ever principally in view; and wherever disputes arise, the question cannot, by any means, be decided with greater certainty, than by ascertaining, on any side, the true interests of mankind. If any false opinion, embraced from appearances, has been found to prevail; as soon as farther experience and sounder reasoning have given us juster notions of human affairs; we retract our first sentiment, and adjust anew the boundaries of moral good and evil.208

\footnotetext{
204 Ibid.

205 Ibid, 1.8 (p. 75).

206 Ibid, 1.9 (p. 75).

207 Not all of morality is guided by this principle, for example, religious forms of morality are not, but Hume thinks that a rational system of morality should be guided by it. ${ }^{208}$ Hume, Second Enquiry, 2.17 (p.81).
} 
Morality for Hume is not unchanging, and is based on experience. We need to experience multiple cases of morality to be able to make inferences pertaining to the good or evil of a particular moral act or fact (i.e. claim), and the more experiences we have the better (as they inform our inferences). Given new experiences, we can change our inferences concerning whether a particular act or fact is good or evil. And, the principle that guides our inferences (that we make via experiences) is verifying based on whether an act or fact is good or evil through its public utility.

To reiterate what I said towards the beginning of this section: consequentialism emphasizes the consequences of an act, the act itself is not so much important as the consequences or ends that it brings about. This puts an emphasis on utility, because if an act is not useful in bringing about a certain endsthen it has no utility within a consequentialist framework. The consequences of any moral action, for Hume, are weighed in light of their public utility within a society. If experience shows us [within the society] that a particular action is no longer good in accordance with public utility, then we can change our guidelines with respect to such actions.

Hume bases the value of his two main virtues for the betterment of society, benevolence and justice, on public utility. But, Hume does not mean virtue in the more traditional virtue ethics, or Aristotelian, understanding of virtue. A virtue for Hume is a virtue only because it is useful in helping to create overall happiness within a society. Hume says at 2.22 of the Second Enquiry,

[It] seems undeniable, that nothing can bestow more merit on any human creature than the sentiment of benevolence in an eminent degree; and that a 
part, at least, of its merit arises from its tendency to promote the interests of our species, and bestow happiness on human society. ${ }^{209}$

Benevolence is a virtue, because of its utility; it is useful in promoting the interests and happiness of "human society". Hume goes on to say of justice at 3.1,

That justice is useful to society, and consequently that part of its merit, at least, must arise from that consideration, it would be a superfluous undertaking to prove. That public utility is the sole origin of justice, and that reflections on the beneficial consequences of this virtue are the sole foundation of its merit [...].210

Hume again stresses public utility. Justice is only a virtue (or valuable), because of its "beneficial consequences" for society—it has no other value than its practical application and the beneficial consequences that arise from it.

These two virtues, benevolence and justice, help society function in such a way as to create the most happiness for the people within society. Again referring back to what I said at the beginning of this section: for indirect consequentialism, the consequences are dependent on the act, but in such a way as to account for outside influences on the act. Therefore, under Hume's moral philosophy, it is not just performing a benevolent act that has desirable consequences (for example, happiness), but, when everyone within a society sees benevolence as a virtue, it becomes a guide for action (and the good consequences stem not only from the benevolent acts but from the virtue of benevolence as well). In this way, Hume is expressing a kind of indirect consequentialism, because the consequences stem not just from acts but also from something external to the acts guiding them as well.

209 Ibid, 2.22 (p. 82).

210 Ibid, 3.1 (p. 83). 
For Hume, morality ${ }^{211}$ has its origins in sentiment. Sentiment is what motivates us to be moral (i.e. "What is honourable, what is fair, what is becoming, what is noble, what is generous, takes possession of the heart, and animates us to embrace and maintain it"212). Reason, though, is still needed, because it is only through many experiences with acts, etc., within society that we can then come to infer what is moral through the understanding. What it comes down to is that we need reason to make inferences from experiences, but what motivates us to be moral is sentiment.

\subsection{Hume's Method in An Enquiry concerning the Principles of Morals}

Despite the way I described Hume's position in the previous section (2.4.

Hume's Moral Philosophy), there is no consensus on whether Hume was any kind of consequentialist or not. It is difficult to pigeonhole Hume with regard to his normative moral theory. In this section, I will qualify Hume's moral philosophy by giving an account of how one can understand Hume's method in An Enquiry concerning the Principles of Morals. This qualification is important for understanding scepticism's reach in Hume's philosophy, and tying together Hume's understanding of metaphysics to his understanding of moral philosophy.

Hume's method throughout the Second Enquiry is a reflective comparison of cases that does not seem to have any intent to assume that it will add up to anything in the end. From Hume's method of comparison of cases (or instances of what might be moral), he draws a kind of general account of what morality might constitute-

\footnotetext{
${ }^{211}$ I am referencing the morality that Hume prescribes to-not all of morality (generally speaking).

212 Hume, Second Enquiry, 1.7 (p. 75).
} 
and looks to see how reason and sentiment might factor into morality. This kind of method does not assume that it will find the ultimate foundation of morality, but is more of a contemplative guess at a framework that morality could possibly operate within. Since it does not seek to find the ultimate foundation of morality, it does not make any definite assertions. In this way, Hume's method keeps his moral philosophy in line with a Moderate, or mitigated, Pyrrhonian Scepticism understanding of his metaphysics, which underpins Hume's philosophy more generally.

In 1.10 of the Second Enquiry, Hume lays out his method,

The only object of reasoning is to discover the circumstances on both sides, which are common to these qualities; to observe that particular in which the estimable qualities agree on the one hand, and the blameable on the other; and thence to reach the foundation of ethics, and find those universal principles, from which all censure or approbation is ultimately derived. As this is a question of fact, not of abstract science, we can only expect success, by following the experimental method, and deducing general maxims from a comparison of particular instances. ${ }^{213}$

Hume himself says that morality "is a question of fact", meaning that morality pertains to experience, and is not something that we can deduce a priori (prior to experience). The experimental method based on experience that Hume speaks about in the above quote is not perfect and infallible. We cannot get to an a priori foundation of morality through reasoning. There needs to be "a comparison of particular instances" (or "cases" as I say in the previous paragraph)—which can only be accomplished through experience-and this comparison will only ever allow us to infer "general maxims" of morality. ${ }^{214}$

\footnotetext{
213 Ibid, 1.10 (pp. 76-77).

214 Of morality, but morality as Hume understands it-not morality at large.
} 
This is a methodology that aims to generalize. ${ }^{215}$ You have this method, its object is to find generalizations, but does it find generalizations? If it does, do those generalizations amount to any kind of certainty or ultimate foundation? Hume seems to infer some generalizations (such a benevolence and justice), but there is no certainty that these are the right generalizations-which means that there is no certainty when it comes moral generalizations. These generalizations are inferences to the best explanation that Hume can find through his comparison of cases. There is nothing that would prevent further comparisons, and further generalizations.

Even Hume's use of utility cannot be used as a foundation, because all it is is a potential candidate for a foundation that seemingly has the potential to produce desirable consequences (when a comparison of cases has been done, it seems that utility can help explain certain general maxims that people seem to take as virtues, like benevolence). But, while utility might help to explain morality when comparing certain cases, Hume's attitude in the Second Enquiry, is still one of uncertainty—an attitude that is underpinned by scepticism. As Hume says, at the very end of Section 1 of the Second Enquiry,

The [...] scientific method, where a general abstract principle is first established, and is afterwards branched out into a variety of inferences and conclusions, may be more perfect itself, but suits less the imperfection of human nature [...]. Men are now cured of their passion for hypotheses and systems in natural philosophy, and will hearken to no arguments but those which are derived from experience. It is full time they should attempt a like reformation in all moral disquisitions; and reject every system of ethics, however subtile or ingenious, which is not founded on fact and observation. ${ }^{216}$

And, then, finishes Section 1 of the Second Enquiry with

\footnotetext{
215 Like, consequentialism, or utilitarianism.

216 Hume, Second Enquiry, 1.10 (p. 77).
} 
We shall begin our enquiry on this head by consideration of the social virtues, benevolence and justice. The explication of them will probably give us an opening by which others may be accounted for. ${ }^{217}$

This is the tone that Hume sets for the rest of the Second Enquiry. He contrasts the experimental method that he sees himself as using with the scientific method more associated with the rationalists who try to found their "general abstract principles" or foundational principles on something that is not based in experience.

His emphasis on experience-that he does make sound like the better option-is not something that will get you certainty in the way that a rationalist would want. The best Hume's method is going to give us is "probably" and "may". This support for a method that can only give us uncertainty at best is underpinned by an unwillingness to accept a priori principles that we have no justification for (based on what we can know). Hume's method leads to a kind of tentative hypothesis, not a sure thing. Hume is telling us (the readers) in advance that whatever he comes up with for a foundation is tentative. This is a kind of fallibilism: providing tentative answers that may or may not be right (with the awareness that the answers may or may not be right, and the acceptance that we may not ever know the right answer). While fallibilism does not necessarily entail scepticism, it does open up the path to scepticism (or can tend toward a sceptical position); especially for someone like Hume, who, throughout his philosophy, is favourably disposed towards scepticism.

217 Ibid, 1.11 (p. 77). My italics. 


\subsection{The Moral Realism and Moral Anti-Realism Debate: Humean Scepticism as an Alternative}

The realism and anti-realism debate in metaphysics is not a new topic of discussion. In the Western Philosophical Tradition, it has roots back to Plato's dialogues. The debate is entrenched in most other fields of philosophy. Take the philosophy of perception, for example. As soon as we ask whether our perceptions are representations of the external world or not (or if our perceptions are accurate representations of the external world or not), we become embroiled in the realism and anti-realism debate. Realism states, generally, that facts (or entities) exist, and that these facts (or entities) are objective and mind-independent in some way. ${ }^{218}$ Anti-realism denies at least one aspect of realism; it can deny that facts (or entities) exist, it can deny that facts (or entities) are objective or mind-independent, or it can reject both of the aforementioned realist claims.

The debate is further made complex by the cognitivism and non-cognitivism differentiation. Cognitivism is traditionally associated with realism, and noncognitivism is traditionally associated with anti-realism. Cognitivism is the view that a fact (or claim, or proposition), like a moral fact (or claim, or proposition), can be true or false. Non-cognitivism, broadly defined, is the view that a fact (or claim, or proposition), like a moral fact (or claim, or proposition), is not truth-apt (cannot be true or false). The importance of this distinction is most noticeable in logic-based arguments, because logic-based arguments treat truth-aptness and true premises (and sound arguments) as highly important. Therefore, for cognitivism to be

${ }^{218}$ I acknowledge that this definition is not without controversy, but it suffices to outline the dichotomy between realism and anti-realism. 
associated with realism and non-cognitivism to be associated with anti-realism has its consequences. Realists think that they have the upper hand, because they can give arguments with truth-apt moral facts making their logic-based arguments stronger. The problem is that there are some anti-realists who are cognitivists, though sometimes in qualified ways (for example, Error Theorists). Overall, the association between cognitivism and realism, and non-cognitivism and anti-realism is misleading - and cognitivism and non-cognitivism should not be associated with realism or anti-realism in particular.

I think that this also holds true when it comes to scepticism, specifically Moderate Pyrrhonian Scepticism. Sceptics in the realism and anti-realism literature often get lumped in with the anti-realists, and so are associated with noncognitivism. But, associating Moderate Pyrrhonian Scepticism with non-cognitivism is not an explicit association, and needs further explanation (which is not usually given). A Pyrrhonian Sceptic remains agnostic (withholds judgement, epochē) when it comes to facts (or claims, or propositions) concerning metaphysics. This does not mean that they outright deny cognitivism or truth-aptness when it comes to metaphysical facts (or claims or propositions). It also means that they do not assert cognitivism or truth-aptness when it comes to metaphysical facts (or claims or propositions). It is their agnosticism that puts Pyrrhonian Sceptics in a position where they cannot affirm or deny anything about the Real, external world. Now, this does not mean that they cannot assert moral claims. It just means that they cannot argue over the metaphysical status of moral claims. 
A Moderate Pyrrhonian Sceptic while maintaining agnosticism about the external world does consent to appearances in order to live their life. In consenting to appearances, they can consent to the appearance of claims. The issue they have is with asserting a metaphysical origin of those claims. In the case of moral claims, the same is true. A Moderate Pyrrhonian Sceptic can assert the moral claim that "Murder is wrong," but what needs to be understood is that they are not asserting anything metaphysical about the putative moral claim. What they are doing is saying that based on appearances, murder appears to be wrong-this is an internal endeavour, not an external endeavour (to use Carnapian language).

This type of Moderate Pyrrhonian Scepticism can be attributed to Hume. Hume says in Book I, Part 4, Section 2 of the Treatise,

[T]he sceptic still continues to reason and believe, even tho' he asserts, that he cannot defend his reason by reason; and by the same rule he must assent to the principle concerning the existence of body, tho' he cannot pretend by any arguments of philosophy to maintain its veracity. Nature has not left this to his choice, and has doubtless esteem'd it an affair of too great importance to be trusted to our uncertain reasonings and speculations. ${ }^{219}$

Even though the sceptic continues to "reason and believe" and cannot help but give in to "the existence of body" (i.e. the external world), they do so without the support of metaphysical arguments. Due to the fallibleness of the human mind-something that cannot be helped (as is the way that humans are)—-the external world is deemed by the sceptic to be something that cannot "be trusted to our uncertain reasonings and speculations." The sceptic is left with assenting to the world of appearances, though they cannot give an argument for the metaphysical origin of those appearances. The scepticism that Hume articulates is a form of Moderate

${ }^{219}$ Hume, A Treatise of Human Nature, 1.4.2.1 (p. 125). 
Pyrrhonian Scepticism, but—since Hume himself shied away from attributing Pyrrhonian Scepticism to his own philosophy (due to a lack of knowledge of Pyrrhonian Scepticism)—I will call Hume's Moderate Pyrrhonian Scepticism just Humean Scepticism.220

On the face of it, it would seem like Humean Scepticism, as with Moderate Pyrrhonian Scepticism, would have to take a non-cognitive stance on the truthaptness of facts (or claims or propositions) - given that a Humean Sceptic would not be able to justify, based on any metaphysical argument, the truth or falsity of the facts. But, a Humean Sceptic could use Carnap's move (when it comes to abstract entities) to be able to apply a kind of qualified truth-aptness to facts within an internal framework. Carnap's initial move is to differentiate between internal and external questions. Internal questions are questions that can be asked within a specified framework (i.e. epistemological questions), while external questions have to do with asking about the reality or existence of the framework as a whole (i.e. metaphysical questions). A Humean Sceptic cannot ask external questions, but they can ask internal questions.

To bring this back into a moral context, take the moral claim, "Murder is wrong," again. Perhaps the society you are a part of practices a form of consequentialism. Murder is wrong within your society's consequentialist moral framework, because a law was created stating that murder is wrong. This law was created in order to bring about the most pleasure or happiness for the society as a

${ }^{220}$ I also call it Humean Scepticism, because it is based on my interpretation of Hume's philosophy to further an argument in metaethics rather than an interpretation of the historic Hume as a piece of Hume scholarship. 
whole, because otherwise people might live in fear that they may be murdered (which is an unpleasant and unhappy way to live). So, for the overall benefit of your society, murder was deemed to be wrong. Within a specified framework, in this case your society's consequentialist moral framework, a fact (or claim or proposition) can be right or wrong, or true or false. It can be true or false, because for someone within your society to state that "Murder is not wrong," for example, would be false given the agreed upon law within your society's consequentialist moral framework. This kind of qualified truth-aptness will not give you the truth or falsity of a fact, etc., with $100 \%$ certainty - it can only give you a probable truth or falsity based on the conditions within the framework at a given time, and cannot state whether a fact is true or false in the external world (in a metaphysical sense).

To connect back to Hume, let us think back to sections $2.2,2.3$, and 2.4 of this paper. For Hume, morality is a social construct, and how we learn it is based on inference (after the experience of something is experienced, preferably, multiple times). This inference via experience is based on our experiences of the appearance of the external world (i.e. our perceptions of the external world)-since our human faculties can only give us "uncertain reasonings and speculations"221 and cannot give us certain metaphysical arguments. For Hume, we cannot know with any certainty that our perceptions of the external world are true or false. But, we can assess whether a fact (or claim or proposition) is true or false based on our inferences and the framework we are operating in (since frameworks, in this understanding, are a

${ }^{221}$ Hume, A Treatise of Human Nature, 1.4.2.1 (p. 125). 
social, internal construction and do not state anything about the Real, external world).

Under Humean Scepticism and Hume's moral philosophy, the moral claim, "Murder is wrong," is true. It is true based on appearances, and within a given internal framework. It cannot be known whether it is true or false from an external, metaphysical stance-the shortcomings of human reasoning (cognitive ability) do not allow us to know this. In an internal sense, moral facts are cognitive (though, with a non-cognitive origin). In an external sense, we cannot know the ultimate metaphysical origin of moral facts. But, what is important is that moral facts are truth-apt for Hume (just in a qualified way based upon a consequentialist moral framework that is socially constructed). If this is true, and Hume's philosophy is cohesive, it looks like Humean Scepticism (combined with Hume's moral philosophy) provides us with an alternative to the traditional moral realism and moral anti-realism dichotomy making the traditional dichotomy an actual debate.

\subsection{Potential Implications}

The purpose of this section is to consider potential implications of Humean Scepticism, Hume's philosophy being cohesive, and Hume's lack of clear distinction between his abstract, metaethical moral philosophy and practical (normative and applied) philosophy. If Hume's philosophy is an actual alternative to the traditional moral realism and moral anti-realism debate, and his philosophy is cohesive; then it is important that we take seriously how we separate fields in moral philosophy. Hume conflates his metaethics and practical philosophy throughout the Second Enquire, but, as shown in section 2.6 of this paper, this does not impede the 
cohesiveness of his philosophy, nor does it produce any contradiction in his moral philosophy.

The potential implication becomes a question for ethics: is the separation of metaethics and practical ethics an arbitrary separation? If it is an arbitrary separation, the line between metaethics and practical ethics is blurry at best, and they interconnect in ways that make them not so easily separable. This is a topic for future thought, but a question to ask is what are the metaethical consequences for practical philosophy, if there are any? And, what is the significance of those consequences for ethics in general? My secret hope behind this paper was to bring attention to how we traditionally view and understand topics (or fields) in philosophy, and question those traditional views. Going forward, I would like readers to consider alternative ways of approaching a topic (or field)—not only in philosophy, but also in all areas of study and knowledge. 


\section{Bibliography}

Blackburn, Simon. Essays in Quasi-Realism. Oxford: Oxford University Press, 1993.

Blackburn, Simon. Oxford Dictionary of Philosophy, Third Edition. Oxford: Oxford University Press, 2016.

Brock, Stuart and Edwin Mares. Realism and Anti-Realism. In Central Problems of Philosophy, edited by John Shand. Montreal and Kingston: McGill-Queen's University Press, 2007.

Carnap, Rudolf. Meaning and Necessity: A Study in Semantics and Modal Logic, Second Edition. Chicago: The University of Chicago Press, 1956.

Collins Pocket Reference English Dictionary, Canadian Edition, s.v. "quasi."

Descartes, René. Meditations in First Philosophy. In The Philosophical Writings of Descartes, Volume II, translated by John Cottingham, Robert Stoothoff, and Dugald Murdoch. Cambridge: Cambridge University Press, 1984.

Empiricus, Sextus. Outlines of Pyrrhonism, translated by R. G. Bury. Cambridge, Massachusetts: Loeb Classical Library, 1933.

Fogelin, Robert J. “The Skeptics Are Coming! The Skeptics Are Coming!” In Pyrrhonian Skepticism, edited by Walter Sinnott-Armstrong, 161-173. Oxford: Oxford University Press, 2004.

Garrett, Don. “'A Small Tincture of Pyrrhonism': Skepticism and Naturalism in Hume's Science of Man.” In Pyrrhonian Skepticism, edited Walter SinnottArmstrong, 68-98. Oxford: Oxford University Press, 2004.

Don Garrett. Cognition and Commitment in Hume's Philosophy. Oxford: Oxford University Press, 1997.

Gascoigne, Neil. Scepticism, in Central Problems of Philosophy, edited by John Shand. Montreal and Kingston: McGill-Queen's University Press, 2002.

Hakkarainen, Jani. "Hume's Scepticism and Realism." British Journal for the History of Philosophy 20, no. 2 (2012): 283-309.

Harman, Gilbert. The Nature of Morality: An Introduction to Ethics. Oxford: Oxford University Press, 1977.

Hume, David. An Enquiry concerning Human Understanding. Edited by Peter Millican. Oxford: Oxford University Press, 2008. 
Hume, David. An Enquiry concerning the Principles of Morals. Edited by Tom L. Beauchamp. Oxford: Oxford University Press, 2009.

Hume, David. A Treatise of Human Nature. Edited by David Fate Norton and Mary J. Norton. Oxford: Oxford University Press, 2009.

Kurtz, Paul. "Darwin re-crucified: why are so many afraid of naturalism." Free Inquiry, Spring 1998. Accessed April 22, 2018, Academic OneFile. http://link.gale group.com.proxy.library.carleton.ca/apps/doc/A20633103/AONE?u=ocul_carlet on\&sid=AONE\&xid=e7e2f9f7.

Mulder, Jesse M. "What Generates the Realism/Anti-Realism Dichotomy." Philosophica 84 (2012): 53-84.

Nicholson, James. "pure mathematics.” In The Concise Oxford Dictionary of Mathematics, Fifth Edition. Oxford: Oxford University Press, 2016. http://www.oxfordreference.com.proxy.library.carleton.ca/view/10.1093/acref/ 9780199679591.001.0001/acref-9780199679591-e-2307.

Papineau, David. "Naturalism," The Stanford Encyclopedia of Philosophy. Edited by Edward N. Zalta, Winter 2016 Edition. Accessed on April 22nd, 2018. https://plato. stanford.edu/archives/win2016/entries/naturalism/.

Plato. Theaetetus. In Complete Works of Plato. Edited by John M. Cooper, and translated M.J. Levett and rev. Myles Burnyeat, 157-234. Indianapolis: Hackett Publishing Company, 1997.

Popkin, Richard H. and José R. Maia Neto, eds. Skepticism: An Anthology. Amherst, New York: Prometheus Books, 2007.

Reid, Thomas. Essays on the Intellectual Powers of Man. Edinburgh: Printed for John Bell, Parliament Square, and G. G. J. \& J. Robinson, London, 1785.

Sayre-McCord, Geoffrey, ed. Essays on Moral Realism. Ithaca, NY: Cornell University Press, 1988.

Shafer-Landau, Russ. Moral Realism: A Defence. Oxford: Oxford University Press, 2009.

Sinnott-Armstrong, Walter. "Consequentialism." The Stanford Encyclopedia of Philosophy. Edited by Edward N. Zalta, Winter 2015 Edition. Accessed on May $29^{\text {th }}, 2018$.

https://plato.stanford.edu/archives/win2015/entries/consequentialism/.

Sinnott-Armstrong, Walter. "Moderate Classy Pyrrhonian Moral Scepticism." The Philosophical Quarterly 58, no. 232 (July 2008): 448-456. 
Strawson, P. F. Skepticism and Naturalism: Some Varieties, The Woodbridge Lectures 1983. New York: Columbia University Press, 1985.

Stroud, Barry. Hume. New York: Routledge \& Kegan Paul plc, 1977.

Sturgeon, Nicholas L. "Moral Explanations" In Essays on Moral Realism. Edited by Geoffrey Sayre-McCord, 229-255. Ithaca, NY: Cornell University Press, 1988. 